\title{
MUST TRY HARDER: EVALUATING THE ROLE OF EFFORT IN EDUCATIONAL ATTAINMENT
}

\author{
Gianni De Fraja, Tania Oliveira, and Luisa Zanchi*
}

\begin{abstract}
The efforts exerted by children, parents, and schools affect the outcome of the education process. We build this idea into a theoretical model where the effort exerted by the three groups of agents is simultaneously determined as a Nash equilibrium. The empirical analysis tests the model using the British National Child Development Study and finds support for this idea. We identify which factors affect educational attainment directly and which indirectly through effort. From a policy perspective, the paper indicates that affecting effort directly would have a positive impact on attainment.
\end{abstract}

\section{Introduction}

$\mathrm{T}$ HIS paper is based on the simple idea that students' educational achievement is affected by the effort put in by those participating in the education process: schools, parents, and, of course, the students themselves. This is natural, and indeed psychologists and educationalists have long been aware of the importance of effort for educational attainment. They usually proxy students' effort with the amount of homework undertaken (Natriello \& McDill, 1986). Empirical research in this area is, however, far from reaching clear conclusions. This is partly due to ambiguities in the interpretation of homework: it could be seen as an indicator of either students' effort, operating at the individual level, or of teachers' effort, operating at the class level (Trautwein \& Köller, 2003). As well as students' effort, the educational psychology literature has also studied the relationship between school attainment and parental effort. Several dimensions of parental effort have been considered, ranging from parents' educational aspirations for their children, to parent-child communication about school matters, to education-related parental supervision at home, and to parents' participation in school activities. As Fan and Chen (2001) note, much of this literature is qualitative rather than quantitative, and most of the quantitative studies rely on simple bivariate correlations. Results are not clear-cut here either: if at all, parental effort appears to affect educational attainment only indirectly, to the extent that it supports children's effort (Hoover-Dempsey et al., 2001).

The lack of specific data quantifying effort as a separate variable affecting educational attainment also hinders economists. For example, Hanushek (1992) proxies parental effort with measures of family socioeconomic status (par-

Received for publication March 14, 2006. Revision accepted for publication September 10, 2008.

* De Fraja: University of Leicester, Università di Roma "Tor Vergata," and CEPR; Oliveira: University of Leicester; Zanchi: University of Leeds.

We thank Karim Abadir, Badi Baltagi, Sarah Brown, Daniele Checchi, Gabriele Fiorentini, Andrea Ichino, Andrew Jones, Sara Lemos, Steve Machin, Kevin Reilly, Karl Taylor, Giovanni Urga, two referees of this REVIEW, and the seminar audience at the Education Department in Leicester, at Essex and in Uppsala for helpful suggestions and comments on an earlier draft. The National Child Development Study data were supplied by the U.K. Data Archive. The authors alone are responsible for the analysis and interpretation in this paper. ents' permanent income and education levels). Intuition, confirmed by our results, would, however, suggest that effort and socioeconomic conditions are in fact distinct variables. Indeed, Becker and Tomes's (1976) theoretical model of optimal parental time allocation suggests a negative relationship between household income and parental effort. ${ }^{1}$ Bonesrønning (1998, 2004), Cooley (2004), and Stinebrickner and Stinebrickner (2008) are among the very few authors in the economics literature who measure the effort exerted by students and parents and estimate its effects on examination results.

Theoretical analyses of the role of effort in the education process are also scarce. ${ }^{2}$ Our paper attempts to fill these gaps by developing a theoretical model of the determination as a Nash equilibrium of the effort exerted by students, their parents, and their schools, and subsequently by estimating empirically the determinants of the effort levels, the interaction among them, and the effect of effort on educational attainment.

We test the theoretical model with the British National Child Development Study (NCDS). This data set is well suited to the study of a structural model of the role of effort on educational achievement, as it contains a large number of variables that can be used as indicators of effort by students, parents, and schools. We measure a student's effort by her attitude-for example, whether she thinks that school is a "waste of time," and by the teacher's views about the student's laziness. Parental effort is measured by their interest in their children's education, how often they read to their children or attend meetings with teachers, and the teacher's perception of this interest. For schools, we use variables such as the extent of parental involvement initiated by the school, whether 16-year-old students are offered career guidance, and the type of disciplinary methods used.

Our empirical estimates of the determinants of effort are encouraging: the theoretical assumption of joint interaction of the effort levels of the three groups of agents appears to

\footnotetext{
${ }^{1}$ Their idea is that parents try to maximize the welfare of their children, and they may decide to allocate more time and effort to their children's education if they perceive limits to their ability to transfer income through inheritance; this is more likely to be the case for low-income families.

${ }^{2}$ This contrasts sharply with the extensive literature that studies the role of effort in firms. A seminal contribution is the theory of efficiency wages (Shapiro \& Stiglitz, 1984), and an extensive survey is provided by Holmstrom and Tirole (1989). There have also been several attempts to estimate empirically the role of effort in firms. An early test of the efficiency wage hypothesis is Cappelli and Chauvin (1991), who measured workers' effort by disciplinary dismissals. More recently, effort has been measured by the propensity to quit (Galizzi \& Lang, 1998), by misconduct (Ichino \& Maggi, 2000), and by absenteeism (Ichino \& Riphahn, 2005). Peer pressure, measured by the presence of a coworker in the same room, also appears to affect a worker's effort (Falk \& Ichino, 2003).
} 
be borne out by the data. Moreover, our measures of effort seem appropriate. For example, as a by-product of our analysis, we find confirmation of Becker's (1960) intuition that there is a trade-off between quantity and quality of children: a child's number of siblings influences negatively the effort exerted by that child's parents toward that child's education.

The econometric model is structural, and therefore it allows us to determine whether explanatory variables influence educational attainment directly or indirectly, that is, via affecting effort. For example, our results suggest that family socioeconomic conditions affect attainment more strongly by effort than directly. In this case, policies that attempt to affect parental effort might be effective ways to improve the educational attainment, since affecting parental effort is likely to be easier than modifying social background. One example could be the provision of direct financial rewards to parents helping their children with homework, or attending parenting classes, similar to the policy of providing financial incentives to disadvantaged teenagers for attending school before (Cardoso \& Souza, 2003) or beyond (Dearden et al., 2003) the compulsory age.

The paper is organized as follows. The theoretical model is developed in section II. The agents' strategic behavior is illustrated in section III with a graphical analysis of the Nash equilibrium. The empirical model is presented in section IV. Section V describes the data and the variables used, and section VI reports our results. Section VII decomposes the direct and indirect effect on attainment, and concluding remarks are in section VIII.

\section{Theoretical Model}

We model the interaction among the pupils at a school, their teachers, and their parents. Pupils attend school, and at the appropriate age, they leave with a qualification. This is a variable $q$ taking one of $m$ possible values $q \in\left\{q_{1}, \ldots\right.$, $\left.q_{m}\right\}$, with $q_{k-1}<q_{k}, k=2, \ldots, m$. Other things equal, a student prefers a better qualification: apart from personal satisfaction, there is substantial evidence showing a positive association between qualification and future earnings in the labor market: let $u(q)$ be the utility associated with qualification $q$, with $u^{\prime}(q)>0$.

When at school, pupils exert effort, which we denote by $e^{C} \in E^{C} \subseteq \mathbb{R}$ (the superscript $C$ stands for "child"). The restriction to single dimensionality is made for algebraic convenience. $e^{C}$ measures how diligent a pupil is, how hard she works, and so on, and it has a utility cost measured by a function $\psi_{C}\left(e^{C}\right)$, increasing and convex: $\psi_{C}^{\prime}\left(e^{C}\right)$, $\psi_{C}^{\prime \prime}\left(e^{C}\right)>0$. Notice that there is no natural scale to measure effort, and so the interpretation of the function $\psi_{C}$ (and the corresponding ones for schools and parents) is cost of effort relative to the benefit of qualification. Pupils also differ in ability, denoted by $a$. A student's educational attainment is affected by her effort and her ability. Formally, we assume that qualification $q_{k}$ is obtained with probability $\pi_{k}\left(e^{C}, a ; \cdot\right)$ (the "." represents other influences on qualification, discussed in what follows). We posit, naturally, a positive relationship between effort and the expected qualification $\sum_{k=1}^{m} \frac{\partial \pi_{k}\left(e^{C}, a ; \cdot\right)}{\partial e^{C}} q_{k}>0$, and between ability and the expected qualification, $\sum_{k=1}^{m} \frac{\partial \pi_{k}\left(e^{C}, a ; \cdot\right)}{\partial a} q_{k}>0$. A student's objective function is the maximization of the difference between expected utility and the cost of effort:

$$
\sum_{k=1}^{m} \pi_{k}\left(e^{C}, a ; \cdot\right) u\left(q_{k}\right)-\psi_{C}\left(e^{C}\right) .
$$

A student's educational attainment depends also on her parents' effort. Parents may help with homework, provide educational experiences (such as museums instead of television), take time to speak to their children's teachers, and so on. We denote this effort by $e^{P} \in E^{P} \subseteq \mathbb{R}$; as before, this is treated as single-dimensional. Consistent with common sense and with the idea that the educational process is best thought of as a long-term process (Hanushek, 1986, and Carneiro \& Heckman, 2005), the variable $e^{P}$ should be viewed as summarizing the influence of parental effort throughout the child's school career: the NCDS data set is well suited to take on board this view, as each subject is observed at three dates: at age 7, at age 11, and at age 16 . Parents differ also in education, social background, and other variables that affect their children's educational attainment; we capture this by means of a multidimensional variable, $s^{P}$.

Parents care about their children's qualification, and so they will exert effort $e^{P}$, which carries a utility cost, measured by the function $\psi_{P}\left(e^{P}\right)$, increasing and convex: $\psi_{P}^{\prime}\left(e^{P}\right), \psi_{P}^{\prime \prime}\left(e^{P}\right)>0$. Parents may have more than one child, and so they care about the expected value of the qualification of all their children. ${ }^{3}$ If parents have $n$ children, their payoff function is given by

$$
\sum_{j=1}^{n} \pi_{k}\left(e_{j}^{C}, a_{j} ; e_{j}^{P}, s^{P} ; \cdot\right) q_{k}-\psi_{P}\left(\sum_{j=1}^{n} e_{j}^{P}\right)
$$

where $e_{j}^{P}$ is the effort devoted by parents to child $j$, whose ability is $a_{j}$ and who exerts effort $e_{j}^{C}$. Since the marginal cost of effort is increasing, a testable prediction of our model is that, all other things equal, parental effort decreases with the

\footnotetext{
${ }^{3}$ Rigorously, we should consider the utility of the qualification, for example, $u_{P}(q)$. It is not in general obvious which shape the function $u_{P}(q)$ should have. Some parents with more than one child may obtain a higher utility gain if the qualification of a child with low attainment is increased than if the qualification of a child whose qualification is already high is increased equivalently. Other parents with more children may value achieving excellence more than avoiding failure and may take an opposite view. Given this potential ambiguity, it seems a good approximation to take the expected attainment of all children as the objective function.
} 
number of children, as proposed in Becker's seminal contribution (1960). ${ }^{4}$

A student's qualification will also be affected by the quality of her school, the last component of the "." in the arguments of the probabilities in equation (1). The school influences its pupils' attainment through its own effort, measured by a variable $e^{S} \in E^{S} \subseteq \mathbb{R}$ (again assumed one-dimensional). This captures the idea that a school can take actions that affect the quality of the education it imparts. Improving the quality of buildings, classroom equipment and sporting facilities, using computers appropriately, and upgrading teachers' qualifications are among the examples. Other examples are the teachers' interest and enthusiasm in their classroom activities and the time they spend outside teaching hours to prepare lessons, assess students' work, meet parents, and so on. ${ }^{5}$ Effort has increasing marginal disutility and can thus be measured by a function $\psi_{S}\left(e^{S}\right)$ increasing and convex, $\psi_{S}^{\prime}\left(e^{S}\right), \psi_{S}^{\prime \prime}\left(e^{S}\right)>0$.

To wrap up this discussion, the probability that a student obtains qualification $q_{k}$ can therefore be written as

$$
\pi_{k}\left(e^{C}, a ; e^{P}, s^{P} ; e^{S}, s^{S}\right)
$$

where, in analogy to $s^{P}, s^{S}$ is a vector that captures the school's exogenously given characteristics. A school's objective function is a function that depends positively on the average qualification of its students and negatively on the teaching effort: ${ }^{6}$

$$
\begin{aligned}
& \sum_{k=1}^{m} q_{k} \sum_{h=1}^{H} \pi_{k}\left(e^{C}(h), a ; e^{P}(h), s^{P} ; e^{S}(h), s^{S}\right) \lambda_{h} \\
& -\psi_{S}\left(e^{S}\right) .
\end{aligned}
$$

Equation (3) assumes that the effort levels $e^{C}, e^{P}$, and $e^{S}$ are affected by a number of exogenous variables described by the multidimensional vector $h$ : thus, $e^{C}(h)$ (respectively, $e^{P}(h)$; respectively, $\left.e^{S}(h)\right)$ is the effort level exerted by students (respectively, parents; respectively, schools) whose vector of relevant variables takes value $h$. $h$ will, of course,

\footnotetext{
${ }^{4}$ We ignore the potential endogeneity of the number of children. Blake (1989) provides a demographic analysis of the relationship between family size and achievement.

${ }^{5}$ Note that the activities in the first group are fixed before the students are enrolled at school and can therefore be observed by parents prior to applying to the school; those in the second group are carried out once the students are at school. Since the extent of school choice was fairly limited in the period covered by our data, this distinction will be disregarded in what follows. The theoretical analysis of De Fraja and Landeras (2006) suggests that a different equilibrium concept should be used according to whether schools and students choose one after the other or simultaneously: Stackelberg and Nash equilibrium, respectively. As they show, this does not affect the qualitative nature of the interaction.

${ }^{6}$ As with parents, the average qualification may not be the most suitable approximation for the school's objective function. Teachers may care more about the best or the weakest students in their class. If this were the case, appropriate weighting could be included to account for these biases in the school's payoff function (3).
}

also include ability and other variables that are also in the vectors $s^{P}$ and $s^{S}$, as these can have a direct effect on qualification, or an indirect effect, via the effort level exerted by the participants in the education process. $H$ is the number of all the possible combinations of values that the variables affecting effort can take, and $\lambda_{h}$ is the proportion of pupils at the school with this variable equal to $h$.

Additivity between the disutility of effort and the students' average qualification is an innocuous normalization. The relative importance of these two components of the school's utility will in general depend on how much teachers care about the success of their pupils, which in turn can depend on government policy: there could be incentives for successful teachers-both monetary and in terms of improved career prospects (see De Fraja \& Landeras, 2006, for theoretical model studies of the effects of strengthening these incentives). The data set we have available, which refers to schools in the late 1960s and early 1970s, is not suited to the study of these effects, since there has been no observable change in the power of the incentive schemes for schools and teachers in that period.

\section{A Graphical Analysis of the Equilibrium}

All agents have a common interest in the realization of a high qualification for the child, but their interests are not perfectly aligned, and their strategic behavior may lead to complex interactions among them, with sometimes counterintuitive outcomes.

In this section, we illustrate this point in an extremely simple case. We assume that all students in a given school are alike. This is obviously unrealistic, but the point here is to illustrate that even with highly special simplifying assumptions, the interaction between the parties may turn out to be extremely complex. We capture this interaction with the game-theoretic concept of Nash equilibrium: each party chooses its effort in order to maximize the utility, taking as given the choice of effort of the other parties. To establish existence and characterize the Nash equilibrium, we impose natural bounds on the effort levels and a constraint on the shape of the function giving the probability of achievement:

Assumption 1. Let $E^{X}=\left[\underline{e}^{X}, \bar{e}^{X}\right], X=C, P, S$, and let the effort functions satisfy $\lim _{e^{X} \rightarrow e^{X}} \psi_{X}^{\prime}\left(e^{X}\right)=0$ and $\lim _{e^{X} \rightarrow \bar{e}^{X}} \psi_{X}^{\prime}\left(e^{X}\right)=+\infty, X=C, P, S$; moreover, let the achievement function $\pi$ satisfy $\frac{\partial^{2} \pi_{k}(\cdot)}{\left(\partial e^{X}\right)^{2}}>0$, for $k=1, \ldots$, $m-1$, and $X=C, P, S$.

In words, the sets $E^{C}, E^{P}$, and $E^{S}$ are closed intervals of $\mathbb{R}$, increasing effort is costless (infinitely costly) when effort is close to its possible minimum (maximum), and, loosely speaking, effort is more effective in reducing the probability of lower qualifications than in increasing the probability of higher ones. 
Proposition 1. Let assumption 1 hold. A Nash equilibrium exists and is given by the set of values $e^{C}, e^{P}$, and $e^{S}$, satisfying the first-order conditions

$$
\begin{aligned}
& \sum_{k=1}^{m} u\left(q_{k}\right) \frac{\partial \pi_{k}\left(e^{C}, a ; e^{P}, s^{P} ; e^{S}, s^{S}\right)}{\partial e^{C}}-\psi_{C}^{\prime}\left(e^{C}\right)=0, \\
& \sum_{k=1}^{m} q_{k} \frac{\partial \pi_{k}\left(e^{C}, a ; e^{P}, s^{P} ; e^{S}, s^{S}\right)}{\partial e^{P}}-\psi_{P}^{\prime}\left(e^{P}\right)=0, \\
& \sum_{k=1}^{m} q_{k} \frac{\partial \pi_{k}\left(e^{C}, a ; e^{P}, s^{P} ; e^{S}, s^{S}\right)}{\partial e^{S}}-\psi_{S}^{\prime}\left(e^{S}\right)=0 .
\end{aligned}
$$

Proof. Each player has a compact and convex strategy space, and therefore a Nash equilibrium exists (Fudenberg \& Tirole, 1991). Differentiation of the left-hand side of equation (4) with respect to $e^{C}$, using the fact that $\sum_{k=1}^{m}$ $\pi_{k}=1$, gives: $\sum_{k=1}^{m-1}\left(u\left(q_{k}\right)-u\left(q_{m}\right)\right) \frac{\partial^{2} \pi_{k}(\cdot)}{\left(\partial e^{C}\right)^{2}}-\psi_{C}^{\prime \prime}\left(e^{C}\right)$. Since $u$ is increasing in $q$ and $\psi_{C}^{\prime \prime}\left(e^{C}\right)>0$, the child's payoff function is quasi-concave; it is also continuous and therefore the first-order condition characterizes the best response. The same is true for the parents and the school.

While extreme, the hypothesis that all students exert the same level of effort can be derived as the Nash equilibrium of a game with a large number of participants played by all the students at a given school, allowing students to have different abilities and different perceptions of their ability (De Fraja \& Landeras, 2006). Therefore, it is as if the school had a single student, and $e^{C}$ can be interpreted as the effort level of this representative student. The conditions imposed in assumption 1, as is usually the case in these situations, are sufficient but not necessary, and could therefore be relaxed at the expense of increased algebraic complexity. It should also be noted that the equilibrium is not necessarily unique. Equations (4) to (6) implicitly define the best reply function ${ }^{7}$ of each of the three agents: their intersections in the space $E^{C} \times E^{P} \times E^{S}$ identify the Nash equilibria. This is best illustrated with a graphical analysis in two dimensions only. Let the parental effort be fixed, at $e^{P}$. Total differentiation of equations (4) and (6) gives the slope of the best reply function in the relevant Cartesian diagram $\left(E^{C} \times E^{S}\right.$ for fixed $e^{P}$ ):

\footnotetext{
${ }^{7}$ Mathematically, for the student, this is a function from the product of the other two effort spaces into the child's: $E^{P} \times E^{S} \rightarrow E^{C}$. This is a dimension two-manifold in the three-dimensional Cartesian space $E^{C} \times$ $E^{P} \times E^{S}$ (analogous for the parents and the school). The intersection of three dimension two-manifolds is (generically) either empty, or a dimension 0-manifold, that is, a set of isolated points. Existence of at least one Nash equilibrium is ensured by the fact that each player has a compact and convex strategy space and that their payoff functions are continuous and quasi-concave in their own strategy (Fudenberg \& Tirole, 1991).
}

Figure 1.-Best Reply Functions of the Representative Student AND THE SCHOOL
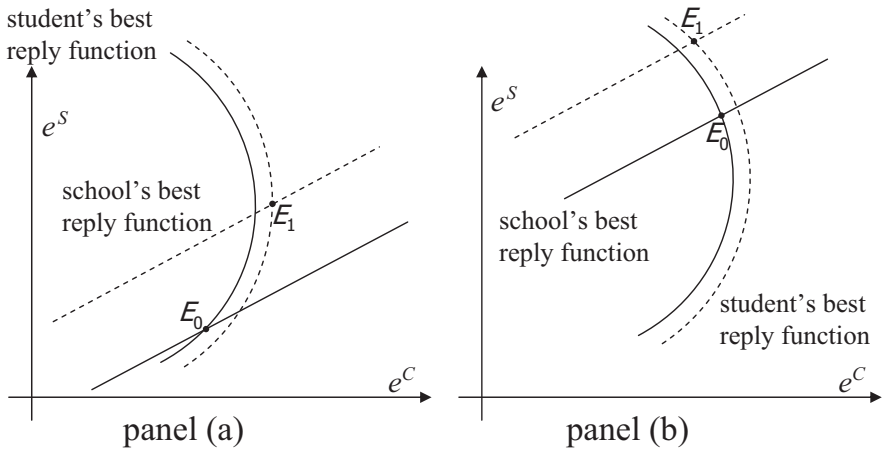

$$
\begin{aligned}
& \left(\sum_{k=1}^{m} u\left(q_{k}\right) \frac{\partial^{2} \pi_{k}(\cdot)}{\partial e^{C} \partial e^{S}}\right) d e^{S}+U_{C}^{\prime \prime}(\cdot) d e^{C}=0, \\
& \left(\sum_{k=1}^{m} q_{k} \frac{\partial^{2} \pi_{k}(\cdot)}{\partial e^{C} \partial e^{S}}\right) d e^{C}+U_{S}^{\prime \prime}(\cdot) d e^{S}=0,
\end{aligned}
$$

where $U_{C}^{\prime \prime}(\cdot)=\sum_{k=1}^{m} u\left(q_{k}\right) \frac{\partial^{2} \pi_{k}(\cdot)}{\left(\partial e^{C}\right)^{2}}-\psi_{C}^{\prime \prime}\left(e^{C}\right)<0$ is the second derivative of the student's payoff, and analogously for $U_{S}^{\prime \prime}(\cdot)$. From the above:

$$
\begin{gathered}
\left.\frac{d e^{S}}{d e^{C}}\right|_{\substack{\text { child } \\
B R F}}=\frac{-U_{C}^{\prime \prime}(\cdot)}{\sum_{k=1}^{m} u\left(q_{k}\right) \frac{\partial^{2} \pi_{k}(\cdot)}{\partial e^{C} \partial e^{S}}}, \\
\left.\frac{d e^{S}}{d e^{C}}\right|_{\substack{\text { school } \\
B R F}}=\frac{\sum_{k=1}^{m} q_{k} \frac{\partial^{2} \pi_{k}(\cdot)}{\partial e^{C} \partial e^{S}}}{-U_{S}^{\prime \prime}(\cdot)} .
\end{gathered}
$$

The signs of the best reply functions depend in general on the sign of the cross-derivatives $\frac{\partial^{2} \pi_{k}(\cdot)}{\partial e^{C} \partial e^{S}}$, that is, on the effect of a small change in a school's (child's) effort on the marginal effect of the child's (school's) effort-in plainer words, on whether the children's and the school's efforts are complements or substitutes. In general, there is no compelling theoretical reason to believe that one is more likely than the other, and therefore both equations (7) and (8) can have either sign at their intersection. Notice, moreover, that in the plausible case where $u(q)$ is not linear, implying that children and schools attribute different importance to relative changes in qualification, they could have opposite signs. ${ }^{8}$ To see what this implies, consider Figure 1. It illustrates the best reply functions for the student and the school. In panel

\footnotetext{
${ }^{8}$ In this special case of one student per school, while the school's and the student's best reply functions can have different signs at their intersection, the parents' and the school's best reply functions have necessarily the same sign.
} 
a, the case is depicted where both equations (7) and (8) are positive at their intersection. The solid lines are the best reply functions associated with the parameter vector $h$ taking value $h_{0}$. The dashed lines depict the best reply functions associated with a different set of exogenous variables, say, $h_{1}$, associated with a higher value of the student's effort, for every given level of the school's effort, and a higher value of the school's effort, for every given level of the student's effort. For example, the dashed lines may represent the best reply functions of the student and the school for a student with higher ability and a larger school (the data suggest that these comparative statics changes are associated with higher effort levels). Graphically, this is a shift upward (for the school) and eastward (for the student) of the best reply function. In panel a, both equilibrium effort levels are higher: compare $E_{0}$ with $E_{1}$.

Consider panel $b$, however. It differs from panel a only in that the best reply functions meet at a point where the student's best reply function is negatively sloped. Again the dashed lines are the best reply functions associated with higher effort levels, ceteris paribus, for both the school and the student, with shifts of similar magnitude as in panel a. In the case depicted in panel $b$, the different values in the exogenous parameters $h$ are associated with a lower equilibrium effort exerted by the student. This is so even though the student's best reply function shifts eastward: $h_{1}$ is associated with higher values in the student's effort for any given level of the school's effort. The reason for the lower equilibrium value of the student's effort is the strategic interaction of schools and students. The vector $h_{1}$ would be associated with a higher value of the student's effort if the school's effort were the same. However, the student's and the school's efforts are "strategic substitutes" (Bulow, Geanakoplos, \& Klemperer, 1985), and the student responds to the higher school's effort (associated with the vector $h_{1}$ ) with a lower level of their own effort. This, in panel $b$ in the diagram, more than compensates for the direct increase in the student's effort caused by the different value of $h$. This simple example illustrates the potential ambiguity of the effects of changes in the exogenous variables $h$ on the equilibrium effort levels. In more general settings, the situation will be even more complex.

\section{Empirical Model}

Given this theoretical ambiguity, the overall effect of children's, parents', and school's efforts on educational attainment, and whether these effort levels are strategic complements or substitutes, is therefore largely an empirical matter, to which we turn in the rest of the paper.

The educational outcome variable considered here, $Q_{i}$, is child $i$ 's academic results over a number of secondary school examinations, normally taken between the ages of 16 and 18 . The explanatory variables are measures of the effort exerted by the child, her parents, and her school, and a suitable set of controls for heterogeneity in ability, socio- economic, demographic, and other relevant factors. Formally, the academic achievement is specified as an educational production function (Hanushek, 1986):

$$
\begin{aligned}
Q_{i} & =\mathbf{x}_{i}^{Q^{\prime}} \boldsymbol{\beta}_{1}+\beta_{2} e_{i}^{C}+\beta_{3} e_{i}^{P}+\beta_{4} e_{i}^{S}+u_{i}, \\
i & =1, \ldots, n,
\end{aligned}
$$

where $e_{i}^{C}, e_{i}^{P}$, and $e_{i}^{S}$ are the measures of the effort exerted by child $i$, child $i$ 's parents, and child $i$ 's school, derived in section $\mathrm{V} ; \mathbf{x}_{i}^{Q}$ are other control variables affecting the educational outcome, and $u_{i}$ is an error term. However, our theoretical analysis in sections II and III suggests that the interaction among the three types of agents is best captured as a Nash equilibrium: the effort levels simultaneously determine each other, and this implies that effort levels are endogenous. We therefore estimate the educational attainment, equation (9), as part of a system also containing equations that determine the Nash equilibrium effort levels. These are equations (4) to (6), an empirical counterpart to which is obtained by taking their linear approximation around the Nash equilibrium:

$$
\begin{array}{ll}
e_{i}^{C}=\mathbf{x}_{i}^{C \prime} \boldsymbol{\gamma}_{1}^{C}+\gamma_{2}^{C} e_{i}^{P}+\gamma_{3}^{C} e_{i}^{S}+v_{i}^{C}, & i=1, \ldots, n, \\
e_{i}^{P}=\mathbf{x}_{i}^{P \prime} \boldsymbol{\gamma}_{1}^{P}+\gamma_{2}^{P} e_{i}^{C}+\gamma_{3}^{P} e_{i}^{S}+v_{i}^{P}, & i=1, \ldots, n, \\
e_{i}^{S}=\mathbf{x}_{i}^{S \prime} \boldsymbol{\gamma}_{1}^{S}+\gamma_{2}^{S} e_{i}^{C}+\gamma_{3}^{S} e_{i}^{P}+\gamma_{i}^{S}, & i=1, \ldots, n,
\end{array}
$$

where $\mathbf{x}_{i}^{C}, \mathbf{x}_{i}^{P}$, and $\mathbf{x}_{i}^{S}$ are the background factors affecting child $i$ 's effort, child $i$ 's parents' effort, and the effort of child $i$ 's school, respectively, and $v_{i}^{C}, v_{i}^{P}$, and $v_{i}^{S}$ are error terms, possibly correlated. In equation $(12), e_{i}^{C}$ on the right-hand side is the effort exerted by the school's representative student at the school attended by child $i$, and similarly for parents.

Our empirical strategy is the estimation of the system of simultaneous equations given by (9) to (12).

To ascertain whether the effort variables are indeed simultaneously determined, we use the Durbin-Wu-Hausman (DWH) augmented regression test suggested by Davidson and MacKinnon (1993). To perform this test, we obtain the residuals from a model of each endogenous right-hand-side variable, $e_{i}^{C}, e_{i}^{P}, e_{i}^{S}$, as a function of all exogenous variables, and include these residuals in the regression of the educational attainment equation, (9). Thus, we first estimate by 3SLS the system

$$
\begin{aligned}
& e_{i}^{C}=\tilde{\mathbf{x}}_{i}^{C \prime} \boldsymbol{\delta}_{1}^{C}+\delta_{2}^{C} e_{i}^{P}+\delta_{3}^{C} e_{i}^{S}+r_{i}^{C}, \\
& e_{i}^{P}=\tilde{\mathbf{x}}_{i}^{P \prime} \boldsymbol{\delta}_{1}^{P}+\delta_{2}^{P} e_{i}^{C}+\delta_{3}^{P} e_{i}^{S}+r_{i}^{P}, \\
& e_{i}^{S}=\tilde{\mathbf{x}}_{i}^{S \prime} \boldsymbol{\delta}_{1}^{S}+\delta_{2}^{S} e_{i}^{C}+\delta_{3}^{S} e_{i}^{P}+r_{i}^{S},
\end{aligned}
$$

where $r_{i}^{C}, r_{i}^{P}$, and $r_{i}^{S}$ are error terms and the vectors $\tilde{\mathbf{x}}_{i}^{C}, \tilde{\mathbf{x}}_{i}^{P}$, and $\tilde{\mathbf{x}}_{i}^{S}$ are the union of the set of variables that form the vectors $\mathbf{x}_{i}^{C}, \mathbf{x}_{i}^{P}$, and $\mathbf{x}_{i}^{S}$ in equations (10) to (12), with the variables that form the vector $\mathbf{x}_{i}^{Q}$ in equation (9) (for 
example, $\tilde{\mathbf{x}}_{i}^{C}$ are background factors affecting either educational attainment or the child's effort, or both; and similarly for $\tilde{\mathbf{x}}_{i}^{P}$ and $\tilde{\mathbf{x}}_{i}^{S}$ ). We then estimate the following augmented regression:

$$
\begin{aligned}
Q_{i}= & \mathbf{x}_{i}^{Q \prime} \boldsymbol{\eta}_{1}+\eta_{2} e_{i}^{C}+\eta_{3} e_{i}^{P}+\eta_{4} e_{i}^{S} \\
& +\eta_{5} \hat{r}_{i}^{C}+\eta_{6} \hat{r}_{i}^{P}+\eta_{7} \hat{r}_{i}^{S}+\tilde{u}_{i},
\end{aligned}
$$

where $\hat{r}_{i}^{C}, \hat{r}_{i}^{P}$, and $\hat{r}_{i}^{S}$ are the residuals obtained from the estimates of equations (13) to (15). If the parameters $\eta_{5}, \eta_{6}$, and $\eta_{7}$ are significantly different from 0 , then estimates of equation (9) are not consistent due to the endogeneity of $e_{i}^{C}$, $e_{i}^{P}$, and $e_{i}^{S}$. We test the null hypothesis $\eta_{5}=\eta_{6}=\eta_{7}=0$. Note that the dependent variable in the educational production function $Q_{i}$ is discrete, and so we adapt the method used for systems of two simultaneous equations-one with a continuous dependent variable and the other with a discrete one (Lewis, 1986). In our case, we have four equations, so we estimate the educational attainment equation using the predicted values $\hat{e}_{i}^{C}, \hat{e}_{i}^{P}$, and $\hat{e}_{i}^{S}$ obtained from a 3SLS estimation ${ }^{9}$ of equations (10) to (12) instead of the three original effort variables: ${ }^{10}$

$$
\begin{aligned}
Q_{i} & =\mathbf{x}_{i}^{Q \prime} \boldsymbol{\beta}_{1}^{*}+\beta_{2}^{*} \hat{e}_{i}^{C}+\beta_{3}^{*} \hat{e}_{i}^{P}+\beta_{4}^{*} \hat{e}_{i}^{S}+u_{i}^{*}, \\
i & =1, \ldots, n .
\end{aligned}
$$

Equation (17) is estimated as an ordered probit, because the educational outcome variable $Q_{i}$ is a discrete ordered variable, taking eleven possible values, as explained in section V. Model specification is based on the general-tospecific procedure (Hendry, 1995). We start from the most general specification of equations (10) to (12) compatible with the order conditions for their identifiability.

The initial exclusion restrictions are discussed next. The child's birth weight is included only in the child's effort equation, (10), since there is no reason that parents, let alone schools, should behave differently depending on a child's birth weight. The father's social class is only in the parents' effort equation, (11). It is not included in children's effort, which should depend on the parents' behavior, not necessarily on their type, and it is not included in the school's effort equation. Although schools may respond to the social class of their pupils' parents, they respond to the average, as captured by the variables measuring the proportion of a child's classmates from a nonmanual family background, we assume them to behave similarly for all their pupils, and not to fine-tune to each child's father's social class. The school size variables appear only in the school's effort equation, (12). While parents and children may respond to class size, we think it reasonable that the overall size of the

\footnotetext{
${ }^{9}$ We estimate equations (10)-(12) with 3SLS, because of the interdependent nature of the effort variables and the possible dependence of the error terms across equations.

${ }^{10}$ For comparison, we also present the estimates of the same equation using the original effort variables; see the last two columns in table 5.
}

school should not affect them. In each case, the corresponding dummy for missing values is also excluded from the equation. To improve the efficiency of our estimates, we subsequently proceed toward a more specific model, excluding plausible variables in one of the three simultaneous equations, testing jointly for acceptable exclusion restrictions at each step, and performing the appropriate sensitivity analysis. Starting from the general model, we have arrived at the more specific model of table 3 by subsequently excluding groups of variables after performing a series of Wald tests to ensure that each exclusion restriction is acceptable. For each group of variables, we have tested for their joint significance in a particular equation, for both the sample of girls and of boys, and stopped when this procedure did not permit us to exclude any other (group of) variable(s). ${ }^{11}$

We then repeat the process for equation (17). From an initial general specification, which includes the predicted values of the three effort variables and all the available exogenous variables, a more parsimonious specification is obtained, again on the groups of joint tests for exclusion restrictions, general goodness of fit, and stability of the estimated parameters. The final model specification is given in the last column of table 2 , where a black dot indicates that the variable is included in the corresponding "column" equation.

\section{Data and Variables}

The NCDS (see CUSSRU, 2000, and JCfLR, 2003, for detailed descriptions) ${ }^{12}$ follows the cohort of individuals born in Great Britain between March 3 and 9, 1958, from birth until the age of 42 . We use information obtained by detailed questionnaires when the individuals were 7,11 , and 16. We also use data from the Public Examinations Survey, also a part of the NCDS, which gives the results of examinations taken until the age of 20 . The data set contains examination results for 7,017 girls and 7,314 boys. After eliminating observations with insufficient information, we were left with a sample of 5,611 girls and 5,860 boys.

\section{A. Dependent Variables}

Effort. The NCDS data set contains many variables that capture aspects of the effort levels $e_{i}^{C}, e_{i}^{P}$, and $e_{i}^{S}$. Described in detail in table 1, these take the form of categorical variables, which have different scales and are in general

\footnotetext{
${ }^{11}$ Intermediate results and the data to obtain them are available on request. At the end of the general-to-specific process, we tested for the joint significance of all the excluded variables (both equation by equation and in the model as a whole). These further Wald tests confirm the acceptability of our exclusion restrictions. We also tested the specific model for the system of equations (10)-(12) for misspecification. The Hausman test statistics are $\chi^{2}(249)=202.26(p$-value 0.9865$)$ for the sample of girls and $\chi^{2}(244)=90.34(p$-value 1$)$ for the sample of boys.

12 This data set is widely used (see http://www.cls.ioe.ac.uk/Cohort/ Ncds/Publications/nwpi.htm). For a discussion of its features, including ways of dealing with nonresponse and attrition problems, see Micklewright (1989) and Connolly, Micklewright, and Nickell (1992).
} 
TABle 1.-Factor Analysis for EfFort Measures

\begin{tabular}{|c|c|c|c|c|c|}
\hline & \multirow[b]{2}{*}{ Range } & \multicolumn{2}{|r|}{ Girls } & \multicolumn{2}{|r|}{ Boys } \\
\hline & & Mean & Scoring Coefficient & Mean & Scoring Coefficient \\
\hline \multicolumn{6}{|l|}{ Child's effort: Variable } \\
\hline School is not a waste of time. & $1-5$ & 4.3012 & 0.0928 & 4.1513 & 0.0955 \\
\hline I get on with classwork. & $1-5$ & 3.4051 & 0.0565 & 3.2500 & 0.0607 \\
\hline Homework is not boring. & $1-5$ & 2.6703 & 0.0810 & 2.4712 & 0.0866 \\
\hline It is not difficult to keep my mind on work. & $1-5$ & 3.3017 & 0.0780 & 3.2406 & 0.0748 \\
\hline I take work seriously. & $1-5$ & 4.1110 & 0.1215 & 4.0319 & 0.1118 \\
\hline I like school. & $1-5$ & 3.4974 & 0.1155 & 3.3705 & 0.1273 \\
\hline There is a point in planning for the future. & $1-5$ & 4.0111 & 0.0286 & 4.0911 & 0.0261 \\
\hline I am always ready to help my teacher. & $1-5$ & 3.6489 & 0.0351 & 3.3033 & 0.0301 \\
\hline I often read in my spare time. & $1-4$ & 3.0814 & 0.0205 & 2.8330 & 0.0260 \\
\hline Age I am likely to leave school. & $1-4$ & 1.9331 & 0.0990 & 1.9019 & 0.1081 \\
\hline I wish I could have left school at 15. & $1-3$ & 2.4167 & 0.2091 & 2.2849 & 0.1894 \\
\hline Teacher thinks child is lazy or hardworking. & $1-5$ & 3.4141 & 0.0624 & 3.0669 & 0.0637 \\
\hline \multicolumn{6}{|l|}{ Parents' effort: Variable } \\
\hline Teacher's opinion of mother's interest in child's education at age 7 & $1-5$ & 3.9961 & 0.0869 & 3.9084 & 0.0827 \\
\hline Teacher's opinion of father's interest in child's education at age 7 & $1-5$ & 2.9653 & 0.0432 & 3.0107 & 0.0521 \\
\hline Mother reads to child at age 7 & $1-4$ & 3.3173 & 0.0319 & 3.3036 & 0.0325 \\
\hline Father reads to child at age 7 & $1-4$ & 3.0037 & 0.0437 & 2.9855 & 0.0503 \\
\hline Father's role in management of child at age 7 & $1-4$ & 3.3706 & 0.0221 & 3.4238 & 0.0251 \\
\hline Parents' initiative to discuss child with teacher at age 7 & $1-2$ & 1.5618 & 0.0413 & 1.5675 & 0.0446 \\
\hline Substantial help from parents for school at age 7 & $1-2$ & 1.5221 & 0.0091 & 1.5218 & 0.0117 \\
\hline Teacher's opinion of mother's interest in child's education at age 11 & $1-5$ & 3.8553 & 0.0867 & 3.7575 & 0.0673 \\
\hline Teacher's opinion of father's interest in child's education at age 11 & $1-5$ & 3.2903 & 0.0811 & 3.3346 & 0.0807 \\
\hline Father's role in management of child at age 11 & $1-4$ & 3.3715 & 0.0162 & 3.4558 & 0.0176 \\
\hline Parents' initiative to discuss child with teacher at age 11 & $1-4$ & 2.0493 & 0.0598 & 2.1055 & 0.0595 \\
\hline Parental hopes about child's school leaving age at age 11 & $1-3$ & 2.6965 & 0.0697 & 2.7152 & 0.0982 \\
\hline Parents want further education for child at age 11 & $1-3$ & 2.7718 & 0.0570 & 2.8222 & 0.0476 \\
\hline Teacher's opinion of mother's interest in child's education at age 16 & $1-5$ & 3.7779 & 0.1267 & 3.6504 & 0.1017 \\
\hline Teacher's opinion of father's interest in child's education at age 16 & $1-5$ & 3.5026 & 0.1060 & 3.4932 & 0.1093 \\
\hline Parents and teacher discuss child at age 16 & $1-4$ & 2.0653 & 0.0404 & 2.1613 & 0.0460 \\
\hline Parents' anxiety over child's school achievement at age 16 & $1-5$ & 3.3967 & 0.0196 & 3.6154 & 0.0220 \\
\hline Parents wish child goes to higher education at age 16 & $1-2$ & 1.3278 & 0.0584 & 1.3323 & 0.0511 \\
\hline \multicolumn{6}{|l|}{ School's effort: Variable } \\
\hline Parent-teacher association in school at age 7 & $1-2$ & 1.1670 & 0.0542 & 1.1667 & 0.0229 \\
\hline Parent-teacher educational meetings arranged at age 7 & $1-2$ & 1.5997 & 0.0501 & 1.5918 & 0.0347 \\
\hline Social functions arranged for parents at age 7 & $1-2$ & 1.5029 & 0.0179 & 1.5013 & 0.0106 \\
\hline Teachers' initiative to discuss child at age 7 & $1-2$ & 1.2314 & 0.0145 & 1.2658 & 0.0146 \\
\hline Teachers' initiative to discuss child at age 11 & $1-2$ & 1.4291 & 0.0103 & 1.4293 & 0.0110 \\
\hline Parent-teacher association in school at age 16 & $1-2$ & 1.6295 & 0.0670 & 1.6456 & 0.0797 \\
\hline Parent-teacher meetings, discussion at age 16 & $1-4$ & 3.0225 & 0.0273 & 3.0151 & 0.0474 \\
\hline Parents are shown teaching methods at age 16 & $1-4$ & 1.5598 & 0.0527 & 1.5794 & 0.0557 \\
\hline Paid career guidance given by teachers at age 16 & $1-2$ & 1.7349 & 0.0346 & 1.7495 & 0.0398 \\
\hline English class streamed at age 16 & $1-2$ & 1.7270 & 0.0624 & 1.7425 & 0.0359 \\
\hline Mathematics class streamed at age 16 & $1-2$ & 1.8672 & 0.1468 & 1.8532 & 0.2108 \\
\hline Disciplinary methods_-suspension at age 16 & $1-3$ & 1.9414 & 0.0534 & 1.9979 & 0.0493 \\
\hline Disciplinary methods_physical/manual activities at age 16 & $1-3$ & 1.3619 & 0.0467 & 1.4755 & 0.0326 \\
\hline Disciplinary methods-extra school work at age 16 & $1-3$ & 2.6245 & 0.0543 & 2.6986 & 0.0340 \\
\hline Disciplinary methods_-detention at age 16 & $1-3$ & 2.4252 & 0.0746 & 2.4601 & 0.1030 \\
\hline Disciplinary methods-report to parents at age 16 & $1-3$ & 2.9216 & 0.0960 & 2.9087 & 0.1022 \\
\hline Disciplinary methods-special reports at age 16 & $1-3$ & 2.6270 & 0.1374 & 2.6890 & 0.1158 \\
\hline
\end{tabular}

noncomparable. We therefore use factor analysis ${ }^{13}$ to construct a single ${ }^{14}$ aggregate continuous index for each of the three effort levels. To account for the ordinal nature of our

${ }^{13}$ We use the principal factor method. Alternative approaches include principal components, principal components factor analysis, and maximumlikelihood factor analysis (Harman, 1976; Everitt \& Dunn, 2001). Since our original variables are defined on an ordinal rather than an interval scale, they are not suited to being analyzed by the maximum-likelihood factor method due to the assumption of normality implied by this procedure. We have also experimented using principal components as an alternative to the principal factor method. The difference in the results provided by the two methods is only of order $10^{-3}$ at most.

${ }^{14}$ We retain one factor for all three effort indices on the basis of scree tests and the structure of item loadings (Costello \& Osborne, 2005). original variables, we perform factor analysis from a matrix of polychoric correlations (Kolenikov \& Angeles, 2004). ${ }^{15}$ Table 1 contains the scoring coefficients for the child's, the parents', and the school's effort indicators (all the results are reported separately for the samples of girls and boys; see note 22 for details). The scoring coefficients are the weights assigned to each effort indicator in the construction of the effort indices. To reduce the loss of information due to

\footnotetext{
15 The STATA routine, which estimates polychoric correlations, can be downloaded from http://www.unc.edu/ skolenik/strata/.
} 
Figure 2.-Density of Effort for Child, Parents, And Schools
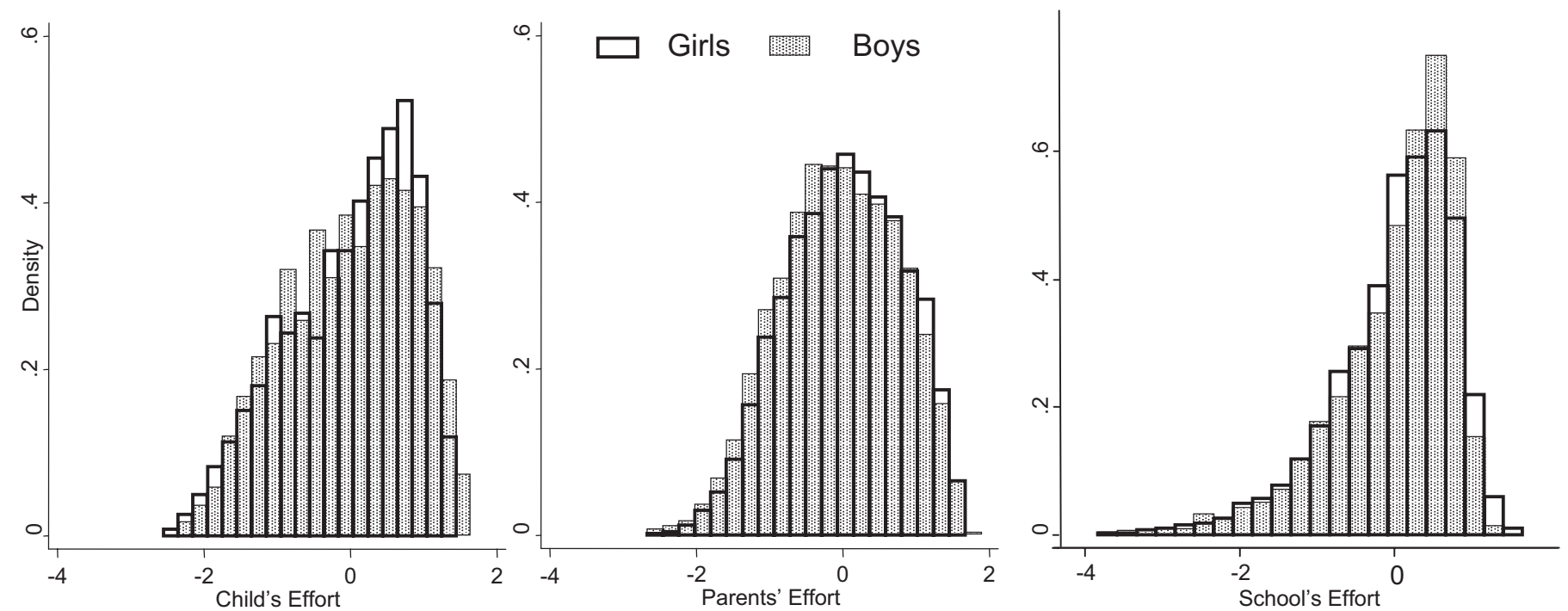

nonresponse, we run an imputation method to obtain factor scores when we have observations with missing data: if some of the variables in table 1 are missing for an observation, the effort variable for that observation is replaced by the predicted value from a linear regression with the nonmissing variables as explanatory variables. Using this method, we have imputed $7 \%, 13.1 \%$, and $6.5 \%$ of the child's, the parents', and the school's effort information, respectively.

The effort indicators used to construct the child's effort measure $e_{i}^{C}$ are the child's answers (at age 16) to questions about her attitude toward school, wishes and expectations about school-leaving age, and the frequency of reading (a higher value denotes higher effort). ${ }^{16}$ This information is complemented by the teacher's assessment of the child's effort when she is 16 (the last row in the top part of table 1). For the children, the variable with the highest weight is whether the child wishes she could have left school at 15, while that with the lowest weight is the frequency of reading in the child's spare time.

The parents' effort measure $e_{i}^{P}$ is produced using the teacher's opinion of both parents' interest in the child's education, their initiative to discuss the child's progress in school, the father's role in the management of the child, the parents' wishes and anxiety over the child's school achievement, and how often parents read to their children. As mentioned in section II, we use information available in three waves of the NCDS to capture the long-term nature of the beneficial effects of parental and school's effort. From the middle part of table 1, we find that the parents' interest in the child's education at different points in time is the most

\footnotetext{
${ }^{16}$ The exact description of how we have constructed these and all the other variables is in an appendix available at http://sites.google.com/site/ giannidefraja/recent-research and on the MIT Press Web site at http:// www.mitpressjournals.org/doi/supp1/10.1162/rest_a_00013. This appendix also reports the factor loadings.
}

salient contributor. On the other hand, whether the parents provide substantial help for school at age 7 and the father's role in the management of the child seem to contribute least to the index.

Our measure of the school's effort, $e_{i}^{S}$, is constructed (see the bottom part of table 1) from information on the extent of activities that school and teachers are not statutorily required to perform, for example, whether teachers take the initiative to discuss a student's progress with her parents, the presence of a parent-teacher association in the school, whether students receive career guidance in the school, and so on. We also include the practice of grouping children of similar ability (streaming). We do so on the grounds that this practice has a cost for the school because of the additional administration and paperwork and because some teachers may dislike it. Finally, we include information on disciplinary methods used, the idea being that activities such as detention or additional homework also require additional work on the teachers' part. The variables with the greatest weight are some disciplinary methods (special reports, reports to parents, and detention) and the practice of streaming in mathematics at age 16. Figure 2 illustrates the density of the effort variables we have constructed.

Examinations. As well as an extremely detailed list of all the examinations taken by each student (obtained in 1978 by writing to schools), the data set also includes a summary measure of the examination performance. This was created (Steedman, 1983a, 1983b) by paying special attention to particular problems such as different timing, grade equivalence, exams taken again, and double entries (see GalindoRueda \& Vignoles, 2003, for an exhaustive discussion of the British education system in the early 1970s). We have taken this measure, modifying it only slightly, to allow inclusion 
Figure 3.-Frequency of Examination Qualifications

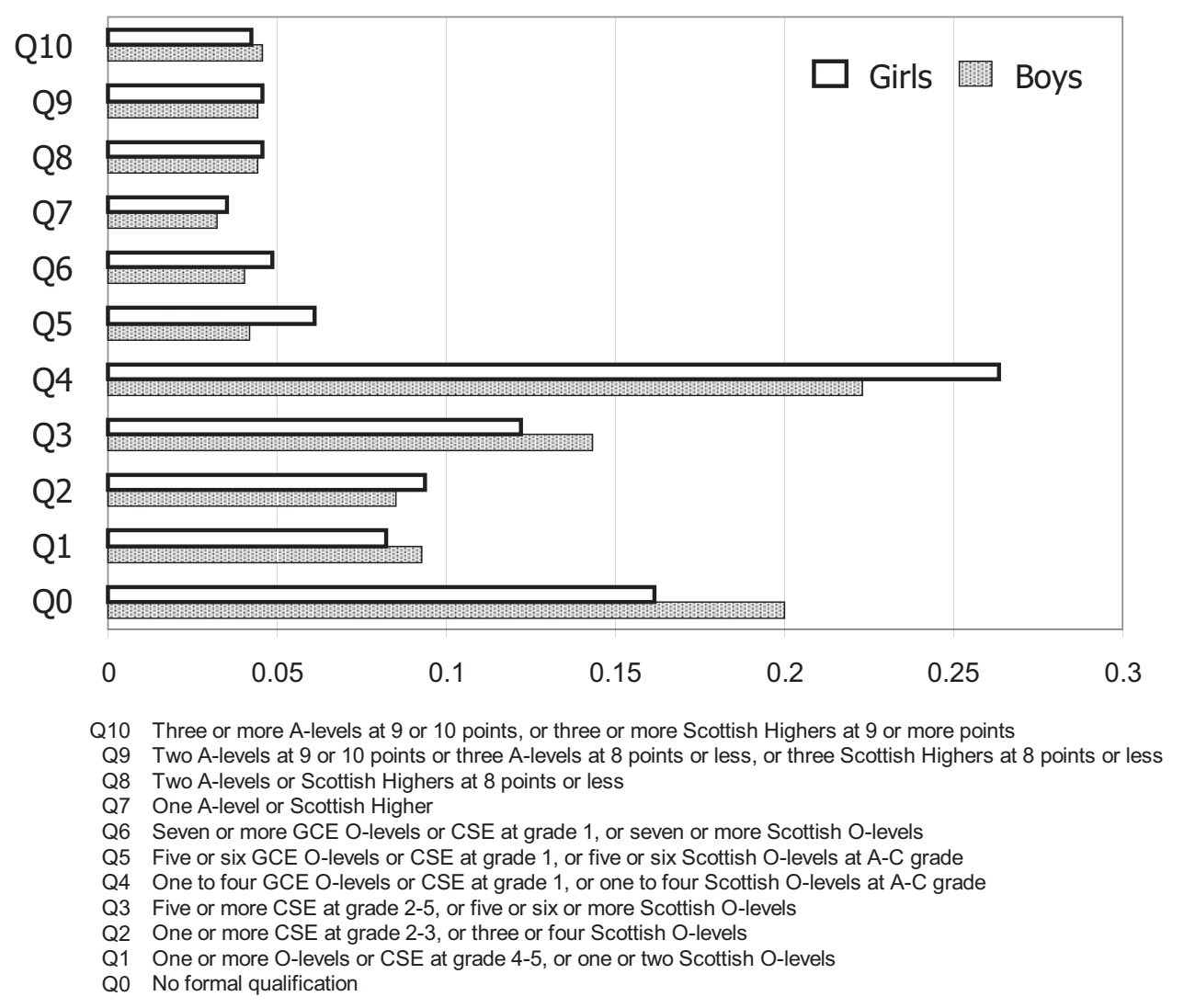

in the sample of the Scottish students. ${ }^{17}$ The educational outcome $Q_{i}$ in equation (17) is a categorical variable ranging from 0 , indicating no formal qualification, to 10 , reflecting three or more A-levels at 9 to 10 points. Figure 3 shows the distribution of examination results for boys and girls in the samples used. The proportion of boys who have at least one A-level result is slightly higher: $17.37 \%$ against $16.66 \%$ for girls. The mode of both distributions is "up to four O-levels or CSE with grade 1.”

\section{B. Explanatory Variables}

The summary statistics for the background explanatory variables are reported in table 2: individual characteristics first, then family characteristics, followed by school, peer group, and geographical variables.

Ability is measured at ages 7,11 , and 16 by administered tests that are independent of educational qualifications. At age 7, there is information on arithmetic and reading scores; at ages 11 and 16, the individuals were tested on their reading and mathematical ability; and at age 11, they also completed a general ability test. Following the literature on

${ }^{17}$ We put together, in Q9, observations of "two A-levels at 9 or 10 points" and "three A-levels at 8 points or less," since there are only 27 observations of the former. Similarly, we have put together, in Q1, "one or more O-levels at grade 4-5" and "one or more CSE at grade 4-5." There are only 70 observations of the former. cognitive ability and students' attainment, we combine the tests undertaken at the different points in time and on different subjects using the principal components method (see, for example, Galindo-Rueda \& Vignoles, 2003). Just as with the effort measures, the ability scale is arbitrary. It may be argued that ability measured at age 11 , and more so at age 16, is a measure of educational achievement rather than an exogenous individual characteristic, despite the endeavor of the test designers. To address this possible pitfall, we repeat all our estimations' measuring ability by the ability score at age 7 only. Results change little. As table 4 shows, measuring ability using only the test scores at age 7 does not affect the relative size of each of the effort variables in the three effort equations, and its effect on child's effort loses significance. Another child-specific variable we include is birth weight in ounces, following some of the literature on lifetime attainment (Conley, Strully, \& Bennett, 2003; Fryer \& Levitt, 2004).

The vector of family background variables includes the number of older and younger brothers and sisters and indicators of the mother's position in the labor market. Parental income is measured when the individuals were $16,{ }^{18}$ and the household socioeconomic status is measured

${ }^{18}$ We manipulated all income information using the procedure developed for this data set by Micklewright (1986). 
TABle 2.-Descriptive Statistics

\begin{tabular}{|c|c|c|c|c|c|c|c|c|}
\hline \multirow[b]{2}{*}{ Variable } & \multicolumn{2}{|c|}{ Girls } & \multicolumn{2}{|c|}{ Boys } & \multirow{2}{*}{$\begin{array}{l}\text { Child's Effort } \\
\text { Equation }\end{array}$} & \multirow{2}{*}{$\begin{array}{l}\text { Parents' Effort } \\
\text { Equation }\end{array}$} & \multirow{2}{*}{$\begin{array}{l}\text { School's Effort } \\
\text { Equation }\end{array}$} & \multirow{2}{*}{$\begin{array}{l}\text { Exam Result } \\
\text { Equation }\end{array}$} \\
\hline & Mean & s.d. & Mean & s.d. & & & & \\
\hline Exam result & 3.716 & 2.771 & 3.542 & 2.918 & - & - & - & - \\
\hline Child's effort & -0.018 & 0.855 & -0.018 & 0.859 & - & $\bullet$ & $\bullet$ & $\bullet$ \\
\hline Parents' effort & 0.010 & 0.791 & 0.006 & 0.793 & $\bullet$ & - & $\bullet$ & $\bullet$ \\
\hline School's effort & -0.001 & 0.764 & 0.001 & 0.775 & $\bullet$ & $\bullet$ & - & $\bullet$ \\
\hline \multicolumn{9}{|l|}{ Child characteristics } \\
\hline $\begin{array}{l}\text { Ability measured at ages } 7,11 \text {, and } 16 \\
\text { a }\end{array}$ & $\begin{array}{r}-0.132 \\
0.006\end{array}$ & 2.243 & $\begin{array}{r}-0.147 \\
0.006\end{array}$ & 2.259 & $\bullet$ & $\bullet$ & & $\bullet$ \\
\hline $\begin{array}{l}\text { Ability measured at age } 7 \\
\text { a }\end{array}$ & $\begin{array}{l}0.000 \\
0.119\end{array}$ & 1.148 & $\begin{array}{l}0.000 \\
0.126\end{array}$ & 1.158 & & & & \\
\hline$\underset{\mathrm{a}}{\text { Weight at birth (ounces) }}$ & $\begin{array}{r}104.763 \\
0.089\end{array}$ & 37.049 & $\begin{array}{r}108.448 \\
0.097\end{array}$ & 39.713 & $\bullet$ & & & \\
\hline \multicolumn{9}{|l|}{ Family characteristics } \\
\hline Older brothers & 0.489 & & 0.483 & & $\bullet$ & $\bullet$ & & $\bullet$ \\
\hline a & 0.209 & & 0.222 & & $\bullet$ & $\bullet$ & & $\bullet$ \\
\hline Younger brothers & 0.513 & & 0.504 & & $\bullet$ & $\bullet$ & & $\bullet$ \\
\hline a & 0.212 & & 0.223 & & $\bullet$ & $\bullet$ & & $\bullet$ \\
\hline Older sisters & 0.447 & & 0.449 & & $\bullet$ & $\bullet$ & & $\bullet$ \\
\hline a & 0.211 & & 0.222 & & $\bullet$ & $\bullet$ & & $\bullet$ \\
\hline Younger sisters & 0.478 & & 0.476 & & $\bullet$ & $\bullet$ & & $\bullet$ \\
\hline a & 0.212 & & 0.224 & & $\bullet$ & $\bullet$ & & $\bullet$ \\
\hline Mother in work age 16 & 0.512 & & 0.513 & & $\bullet$ & $\bullet$ & & $\bullet$ \\
\hline a & 0.215 & & 0.222 & & $\bullet$ & $\bullet$ & & $\bullet$ \\
\hline Mother in work age 7 & 0.251 & & 0.235 & & $\bullet$ & $\bullet$ & & $\bullet$ \\
\hline a & 0.137 & & 0.147 & & $\bullet$ & $\bullet$ & & $\bullet$ \\
\hline Mother married at birth & 0.903 & & 0.907 & & & & & $\bullet$ \\
\hline a & 0.063 & & 0.063 & & & & & $\bullet$ \\
\hline House owner & 0.403 & & 0.394 & & $\bullet$ & $\bullet$ & $\bullet$ & $\bullet$ \\
\hline a & 0.202 & & 0.213 & & $\bullet$ & $\bullet$ & $\bullet$ & $\bullet$ \\
\hline Total household income ( $£$ per week) & 32.031 & 27.038 & 31.399 & 26.494 & $\bullet$ & $\bullet$ & $\bullet$ & $\bullet$ \\
\hline a & 0.286 & & 0.293 & & $\bullet$ & $\bullet$ & $\bullet$ & $\bullet$ \\
\hline$\%$ of income not from father & 0.290 & 0.336 & 0.289 & 0.334 & $\bullet$ & $\bullet$ & $\bullet$ & $\bullet$ \\
\hline Free school meals in school age 11 & 0.085 & & 0.080 & & $\bullet$ & $\bullet$ & $\bullet$ & $\bullet$ \\
\hline a & 0.163 & & 0.170 & & $\bullet$ & $\bullet$ & $\bullet$ & $\bullet$ \\
\hline Financial hardship at 11 & 0.110 & & 0.103 & & $\bullet$ & $\bullet$ & $\bullet$ & $\bullet$ \\
\hline a & 0.161 & & 0.165 & & $\bullet$ & $\bullet$ & $\bullet$ & $\bullet$ \\
\hline Father has higher education & 0.075 & & 0.077 & & $\bullet$ & $\bullet$ & $\bullet$ & $\bullet$ \\
\hline Father has secondary education & 0.257 & & 0.245 & & $\bullet$ & $\bullet$ & $\bullet$ & $\bullet$ \\
\hline a & 0.230 & & 0.237 & & $\bullet$ & $\bullet$ & $\bullet$ & $\bullet$ \\
\hline Mother has higher education & 0.055 & & 0.046 & & $\bullet$ & $\bullet$ & $\bullet$ & $\bullet$ \\
\hline Mother has secondary education & 0.363 & & 0.359 & & $\bullet$ & $\bullet$ & $\bullet$ & $\bullet$ \\
\hline a & 0.213 & & 0.226 & & $\bullet$ & $\bullet$ & $\bullet$ & $\bullet$ \\
\hline Father reads books regularly & 0.427 & & 0.423 & & $\bullet$ & $\bullet$ & $\bullet$ & $\bullet$ \\
\hline Father reads books occasionally & 0.169 & & 0.166 & & $\bullet$ & $\bullet$ & $\bullet$ & $\bullet$ \\
\hline a & 0.134 & & 0.140 & & $\bullet$ & $\bullet$ & $\bullet$ & $\bullet$ \\
\hline Mother reads books regularly & 0.301 & & 0.291 & & $\bullet$ & $\bullet$ & $\bullet$ & $\bullet$ \\
\hline Mother reads books occasionally & 0.188 & & 0.185 & & $\bullet$ & $\bullet$ & $\bullet$ & $\bullet$ \\
\hline a & 0.135 & & 0.141 & & $\bullet$ & $\bullet$ & $\bullet$ & $\bullet$ \\
\hline Father socioeconomic status: Intermediate ${ }^{\mathrm{b}}$ & 0.159 & & 0.144 & & & $\bullet$ & & \\
\hline $\begin{array}{l}\text { Father socioeconomic status: Skilled } \\
\text { nonmanual }^{\text {b }}\end{array}$ & 0.079 & & 0.080 & & & $\bullet$ & & \\
\hline $\begin{array}{l}\text { Father socioeconomic status: Skilled } \\
\text { manual }^{\text {b }}\end{array}$ & 0.346 & & 0.345 & & & $\bullet$ & & \\
\hline $\begin{array}{l}\text { Father socioeconomic status: Semiskilled } \\
\text { nonmanual }^{\text {b }}\end{array}$ & 0.018 & & 0.017 & & & $\bullet$ & & \\
\hline $\begin{array}{l}\text { Father socioeconomic status: Semiskilled } \\
\text { manual }^{\text {b }}\end{array}$ & 0.127 & & 0.125 & & & $\bullet$ & & \\
\hline Father socioeconomic status: Unskilled ${ }^{\mathrm{b}}$ & 0.046 & & 0.051 & & & $\bullet$ & & \\
\hline a & 0.178 & & 0.185 & & & $\bullet$ & & \\
\hline \multicolumn{9}{|l|}{ School characteristics } \\
\hline English class size age 16 & 24.710 & 7.947 & 24.043 & 8.050 & $\bullet$ & & $\bullet$ & $\bullet$ \\
\hline$(\text { English class size age } 16)^{2}$ & 673.728 & 321.876 & 642.881 & 316.650 & $\bullet$ & & $\bullet$ & $\bullet$ \\
\hline a & 0.050 & & 0.051 & & $\bullet$ & & $\bullet$ & $\bullet$ \\
\hline Math class size age 16 & 23.832 & 8.373 & 23.765 & 8.207 & $\bullet$ & & $\bullet$ & $\bullet$ \\
\hline$(\text { Math class size age } 16)^{2}$ & 638.054 & 332.037 & 632.104 & 326.054 & $\bullet$ & & $\bullet$ & $\bullet$ \\
\hline a & 0.056 & & 0.052 & & $\bullet$ & & $\bullet$ & $\bullet$ \\
\hline No. children in child's present class age 7 & 31.254 & 13.309 & 30.700 & 13.688 & $\bullet$ & & $\bullet$ & $\bullet$ \\
\hline$(\text { No. children in child's present class age } 7)^{2}$ & $1,153.894$ & 610.691 & $1,129.817$ & 624.551 & $\bullet$ & & $\bullet$ & $\bullet$ \\
\hline a & 0.116 & & 0.125 & & $\bullet$ & & $\bullet$ & $\bullet$ \\
\hline No. children in child's present class age 11 & 29.129 & 14.278 & 28.748 & 14.443 & $\bullet$ & & $\bullet$ & $\bullet$ \\
\hline (No. children in child's present class age 11$)^{2}$ & $1,052.319$ & 625.554 & $1,035.040$ & 651.123 & $\bullet$ & & $\bullet$ & $\bullet$ \\
\hline a & 0.157 & & 0.159 & & $\bullet$ & & $\bullet$ & $\bullet$ \\
\hline
\end{tabular}


TABLE 2.-(CONTINUED)

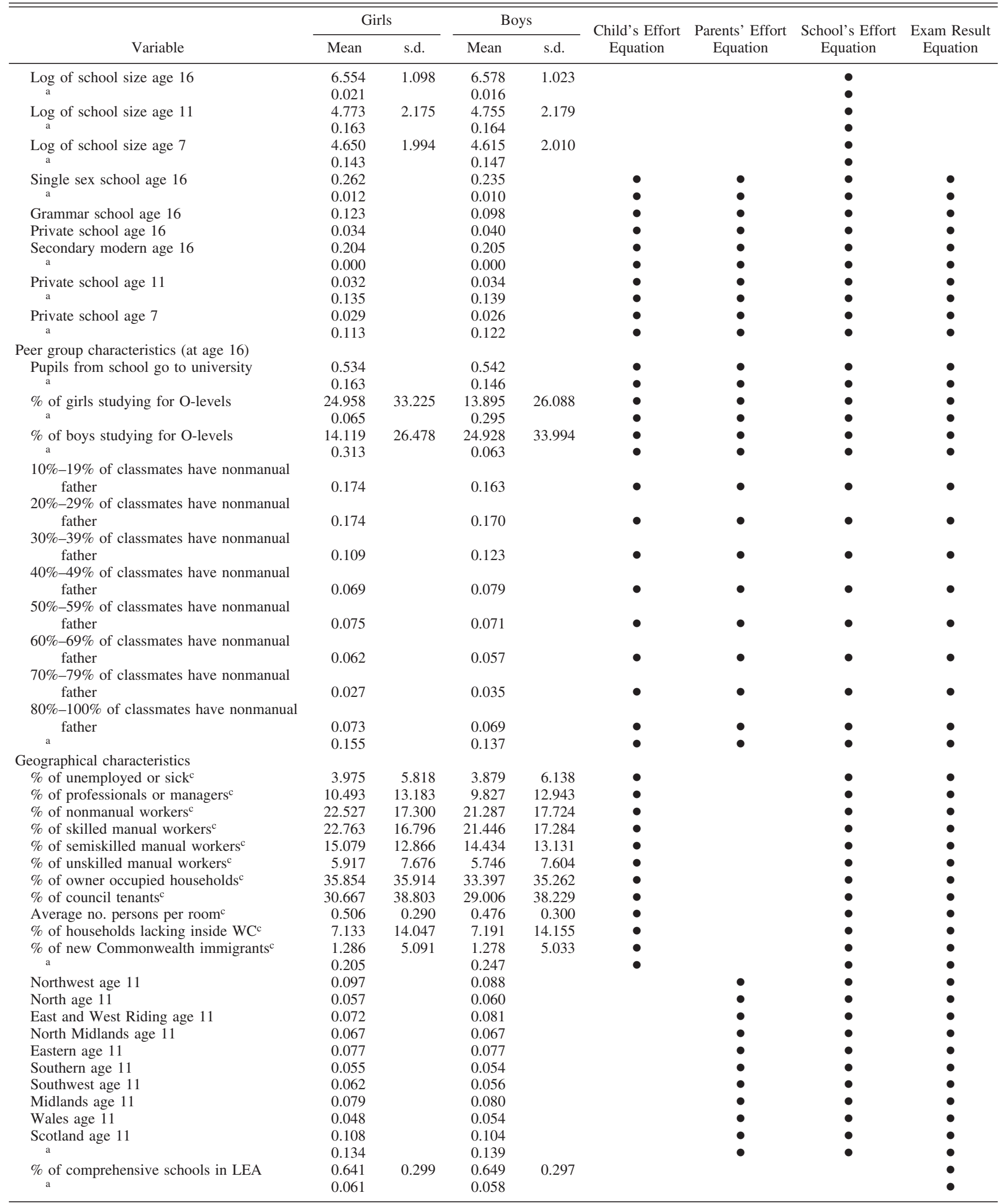

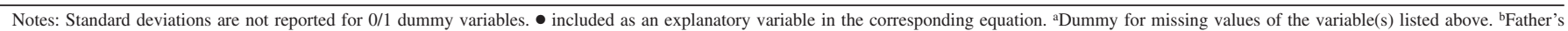
socioeconomic status, at age 11 (reference group: Father's Socio-Economic Status Managerial). 'Enumeration district-level variables from 1971 Census Small Area Statistics. 
THE REVIEW OF ECONOMICS AND STATISTICS

Table 3.-Three-Stage Least Squares Estimates of Effort Equations

\begin{tabular}{|c|c|c|c|c|c|c|c|c|c|c|c|c|}
\hline \multirow{3}{*}{$\begin{array}{c}\text { Dependent Variable } \\
\text { Variable }\end{array}$} & \multicolumn{4}{|c|}{ Child's Effort } & \multicolumn{4}{|c|}{ Parents' Effort } & \multicolumn{4}{|c|}{ School's Effort } \\
\hline & \multicolumn{2}{|c|}{ Girls } & \multicolumn{2}{|c|}{ Boys } & \multicolumn{2}{|c|}{ Girls } & \multicolumn{2}{|c|}{ Boys } & \multicolumn{2}{|c|}{ Girls } & \multicolumn{2}{|c|}{ Boys } \\
\hline & Coef. & s.e. & Coef. & s.e. & Coef. & s.e. & Coef. & s.e. & Coef. & s.e. & Coef. & s.e. \\
\hline Constant & 0.011 & 0.249 & 0.319 & 0.238 & 0.098 & 0.082 & -0.063 & 0.084 & $-4.661 * *$ & 0.254 & $-5.055 * *$ & 0.234 \\
\hline Child's effort & & & & & $0.323 * *$ & 0.068 & $0.310^{* *}$ & 0.066 & $0.190 *$ & 0.092 & $0.173 *$ & 0.071 \\
\hline Parents' effort & $0.517 * *$ & 0.091 & $0.664 * *$ & 0.083 & & & & & 0.021 & 0.093 & 0.062 & 0.083 \\
\hline School's effort & $-0.178 * *$ & 0.037 & $-0.124 * *$ & 0.035 & -0.061 & 0.032 & -0.046 & 0.027 & & & & \\
\hline Child characteristics & & & & & & & & & & & & \\
\hline Ability & $0.085^{* *}$ & 0.013 & $0.076 * *$ & 0.011 & $0.072 * *$ & 0.012 & $0.067 * *$ & 0.012 & & & & \\
\hline Weight at birth (ounces) & $-0.001 *$ & 0.001 & $-0.002 * *$ & 0.000 & & & & & & & & \\
\hline Family characteristics & & & & & & & & & & & & \\
\hline Older brothers & -0.012 & 0.014 & 0.001 & 0.013 & $-0.042 * *$ & 0.011 & $-0.035^{* *}$ & 0.010 & & & & \\
\hline Younger brothers & -0.018 & 0.014 & 0.005 & 0.013 & $-0.029 * *$ & 0.011 & -0.009 & 0.010 & & & & \\
\hline Older sisters & -0.006 & 0.015 & -0.004 & 0.014 & $-0.065 * *$ & 0.011 & $-0.051 * *$ & 0.011 & & & & \\
\hline Younger sisters & 0.010 & 0.014 & 0.024 & 0.014 & $-0.045 * *$ & 0.010 & $-0.039 * *$ & 0.011 & & & & \\
\hline Mother in work age 16 & -0.013 & 0.026 & -0.006 & 0.026 & 0.032 & 0.021 & $0.056^{* *}$ & 0.021 & & & & \\
\hline Mother in work age 7 & -0.007 & 0.025 & 0.019 & 0.024 & $-0.047 *$ & 0.019 & $-0.045^{*}$ & 0.019 & & & & \\
\hline Houseowner & 0.051 & 0.030 & -0.042 & 0.030 & $0.101 * *$ & 0.023 & $0.126^{* *}$ & 0.021 & 0.036 & 0.025 & 0.002 & 0.025 \\
\hline $\begin{array}{l}\text { Total household income } \\
\quad(£ \text { per week })\end{array}$ & 0.000 & 0.001 & $-0.002 * *$ & 0.001 & 0.000 & 0.001 & $0.002 * *$ & 0.001 & 0.001 & 0.001 & 0.001 & 0.001 \\
\hline $\begin{array}{l}\% \text { of income not from } \\
\text { father }\end{array}$ & 0.001 & 0.043 & 0.026 & 0.043 & $-0.077 *$ & 0.033 & $-0.113 * *$ & 0.033 & $0.116^{* * *}$ & 0.035 & -0.009 & 0.034 \\
\hline $\begin{array}{l}\text { Free school meals in } \\
\text { school age } 11\end{array}$ & 0.024 & 0.042 & 0.044 & 0.044 & $-0.083^{*}$ & 0.033 & $-0.148 * *$ & 0.033 & -0.042 & 0.037 & -0.046 & 0.037 \\
\hline Financial hardship at 11 & 0.045 & 0.038 & 0.015 & 0.036 & $-0.111 * *$ & 0.029 & $-0.066^{*}$ & 0.028 & -0.027 & 0.034 & 0.035 & 0.031 \\
\hline $\begin{array}{l}\text { Father has higher } \\
\text { education }\end{array}$ & -0.045 & 0.047 & $0.113 *$ & 0.045 & 0.055 & 0.037 & -0.003 & 0.037 & -0.041 & 0.041 & -0.052 & 0.039 \\
\hline $\begin{array}{l}\text { Father has secondary } \\
\text { education }\end{array}$ & 0.003 & 0.028 & -0.012 & 0.028 & 0.008 & 0.022 & 0.020 & 0.022 & $-0.052 *$ & 0.025 & 0.018 & 0.024 \\
\hline $\begin{array}{l}\text { Mother has higher } \\
\text { education }\end{array}$ & 0.016 & 0.055 & $-0.112 *$ & 0.057 & $0.133 * *$ & 0.043 & $0.126^{* *}$ & 0.044 & 0.005 & 0.047 & -0.015 & 0.049 \\
\hline $\begin{array}{l}\text { Mother has secondary } \\
\text { education }\end{array}$ & -0.029 & 0.028 & -0.024 & 0.027 & $0.070 * *$ & 0.021 & 0.015 & 0.021 & 0.038 & 0.024 & -0.036 & 0.022 \\
\hline $\begin{array}{l}\text { Father reads books } \\
\text { regularly }\end{array}$ & $-0.038 *$ & 0.035 & -0.038 & 0.033 & $0.186 * *$ & 0.023 & $0.161 * *$ & 0.023 & 0.007 & 0.029 & $-0.064^{*}$ & 0.027 \\
\hline $\begin{array}{l}\text { Father reads books } \\
\text { occasionally }\end{array}$ & -0.027 & 0.035 & -0.032 & 0.033 & $0.134 * *$ & 0.026 & $0.078 * *$ & 0.026 & 0.048 & 0.030 & -0.040 & 0.028 \\
\hline $\begin{array}{l}\text { Mother reads books } \\
\text { regularly }\end{array}$ & -0.023 & 0.029 & $-0.065^{*}$ & 0.030 & $0.093 * *$ & 0.022 & $0.134 * *$ & 0.022 & -0.041 & 0.025 & 0.015 & 0.026 \\
\hline $\begin{array}{l}\text { Mother reads books } \\
\text { occasionally }\end{array}$ & -0.003 & 0.030 & -0.035 & 0.030 & $0.054 *$ & 0.023 & $0.089 * *$ & 0.023 & -0.043 & 0.026 & -0.028 & 0.026 \\
\hline $\begin{array}{l}\text { Father socioeconomic } \\
\text { status: Intermediate }\end{array}$ & & & & & -0.061 & 0.037 & -0.017 & 0.033 & & & & \\
\hline $\begin{array}{l}\text { Father socioeconomic } \\
\text { status: Skilled }\end{array}$ & & & & & & & & & & & & \\
\hline nonmanual $^{\mathrm{a}}$ & & & & & $-0.125^{* *}$ & 0.042 & $-0.074^{*}$ & 0.038 & & & & \\
\hline $\begin{array}{l}\text { Father socioeconomic } \\
\text { status: Skilled }\end{array}$ & & & & & & & & & & & & \\
\hline manual $^{\mathrm{a}}$ & & & & & $-0.259 * *$ & 0.040 & $-0.220^{* *}$ & 0.037 & & & & \\
\hline $\begin{array}{l}\text { Father socioeconomic } \\
\text { status: Semiskilled } \\
\text { nonmanual }^{\mathrm{a}}\end{array}$ & & & & & $-0.189 * *$ & 0.063 & $-0.207 * *$ & 0.059 & & & & \\
\hline $\begin{array}{l}\text { Father socioeconomic } \\
\text { status: Semiskilled } \\
\text { manual }^{\mathrm{a}}\end{array}$ & & & & & $-0.223^{* *}$ & 0.043 & $-0.223 * *$ & 0.041 & & & & \\
\hline $\begin{array}{c}\text { Father socioeconomic } \\
\text { status: Unskilled }\end{array}$ & & & & & $-0.334 * *$ & 0.054 & $-0.309 * *$ & 0.049 & & & & \\
\hline $\begin{array}{l}\text { School characteristics } \\
\text { English class size age }\end{array}$ & & & & & & & & & & & & \\
\hline $\begin{array}{l}16 \\
\text { (English class size age }\end{array}$ & 0.014 & 0.010 & 0.005 & 0.009 & & & & & $0.052^{* * *}$ & 0.010 & $0.053 * *$ & 0.009 \\
\hline 16$)^{2}$ & 0.000 & 0.000 & 0.000 & 0.000 & & & & & $-0.001 * *$ & 0.000 & $-0.001 * *$ & 0.000 \\
\hline $\begin{array}{l}\text { Math class size age } 16 \\
\text { (Math class size age }\end{array}$ & 0.003 & 0.009 & -0.006 & 0.009 & & & & & 0.006 & 0.009 & $0.029 * *$ & 0.009 \\
\hline 16$)^{2}$ & 0.000 & 0.000 & 0.000 & 0.000 & & & & & 0.000 & 0.000 & $-0.001 * *$ & 0.000 \\
\hline $\begin{array}{l}\text { No. children in child's } \\
\text { present class age } 7 \\
\text { (No. children in child's }\end{array}$ & 0.007 & 0.007 & 0.003 & 0.006 & & & & & 0.004 & 0.008 & $0.017 *$ & 0.007 \\
\hline present class age 7$)^{2}$ & 0.000 & 0.000 & 0.000 & 0.000 & & & & & 0.000 & 0.000 & $0.000 *$ & 0.000 \\
\hline
\end{tabular}


TABLE 3.-(CONTINUED)

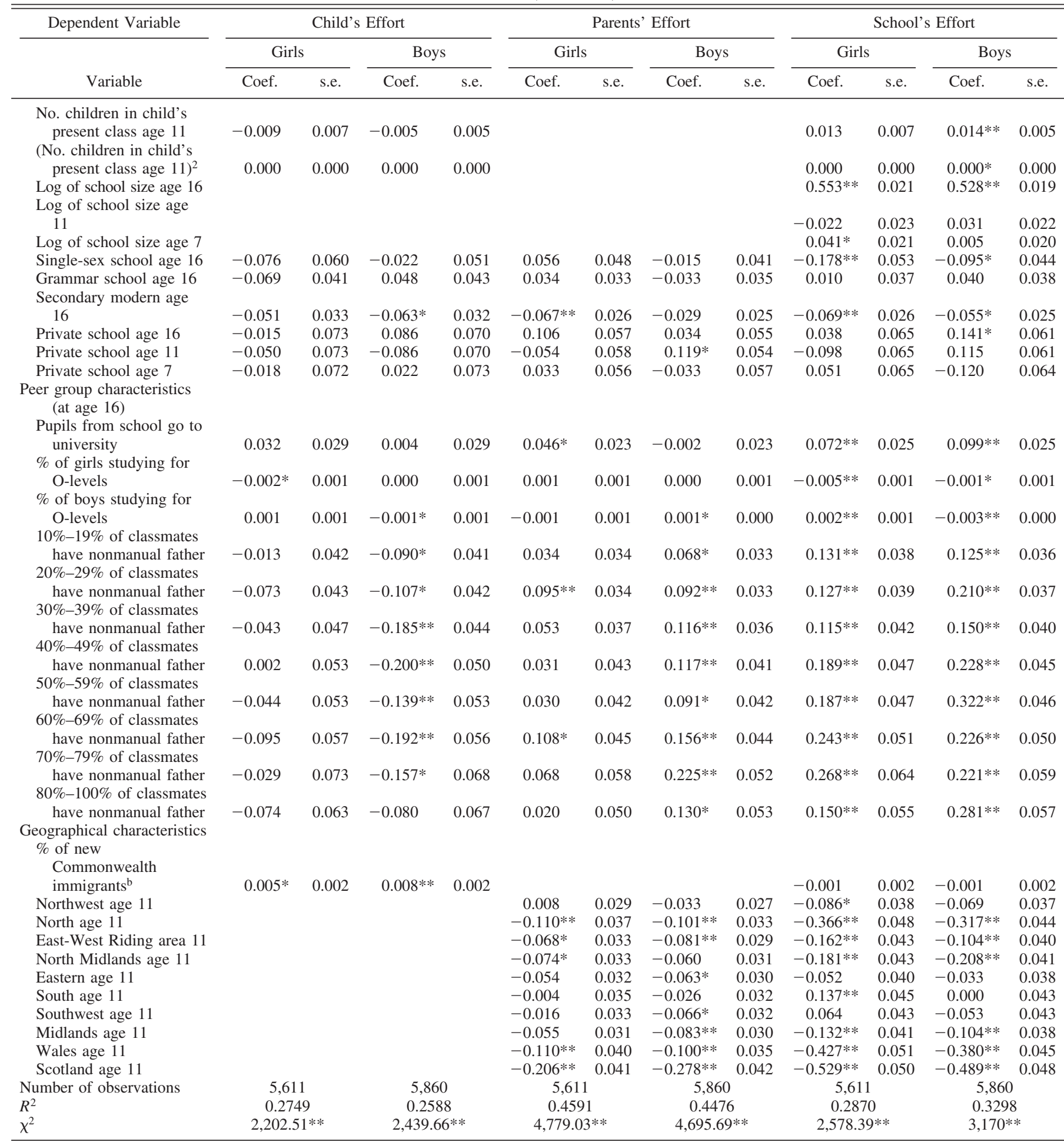

aFather's socioeconomic status, at age 11 (reference group: Father's Socio-Economic Status Managerial). Other variables included in the model and not reported are: father's socioeconomic status unclassifiable,

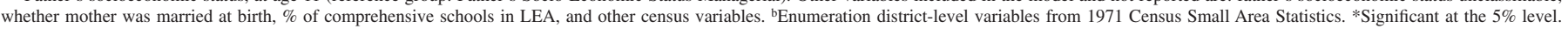
** Significant at the $1 \%$ level.

by the father's (or the father figure's) social class at age 11 . We have also included the percentage of total income not earned by the father figure, whether the household's accommodation is owned by the household, whether any child in the household receives free school meals, and whether the household experiences serious financial hardship. Other variables are parental educational attainment and the frequency of reading by parents, as distinct from the variable 
Table 4.-Three-Stage Least Squares Estimates of Effort Equations with Age 7 Ability Only

\begin{tabular}{|c|c|c|c|c|c|c|c|c|c|c|c|c|}
\hline \multirow{3}{*}{$\begin{array}{c}\text { Dependent Variable } \\
\text { Variable }\end{array}$} & \multicolumn{4}{|c|}{ Child's Effort } & \multicolumn{4}{|c|}{ Parents' Effort } & \multicolumn{4}{|c|}{ School's Effort } \\
\hline & \multicolumn{2}{|c|}{ Girls } & \multicolumn{2}{|c|}{ Boys } & \multicolumn{2}{|c|}{ Girls } & \multicolumn{2}{|c|}{ Boys } & \multicolumn{2}{|c|}{ Girls } & \multicolumn{2}{|c|}{ Boys } \\
\hline & Coef. & s.e. & Coef. & s.e. & Coef. & s.e. & Coef. & s.e. & Coef. & s.e. & Coef. & s.e. \\
\hline Constant & -0.420 & 0.233 & -0.104 & 0.213 & 0.046 & 0.083 & -0.116 & 0.082 & $-4.659 * *$ & 0.253 & $-5.016 * *$ & 0.232 \\
\hline Child's effort & & & & & $0.441 * *$ & 0.053 & $0.447 * *$ & 0.048 & 0.150 & 0.130 & 0.102 & 0.088 \\
\hline Parents' effort & $0.646 * *$ & 0.082 & $0.777 * *$ & 0.076 & & & & & 0.044 & 0.101 & 0.145 & 0.078 \\
\hline School's effort & $-0.168 * *$ & 0.037 & $-0.125 * *$ & 0.035 & -0.015 & 0.030 & -0.009 & 0.026 & & & & \\
\hline Ability & $0.034 *$ & 0.017 & 0.011 & 0.016 & $0.085^{* *}$ & 0.012 & $0.085 * *$ & 0.012 & & & & \\
\hline Number of observations & \multicolumn{2}{|c|}{5,611} & \multicolumn{2}{|c|}{5,860} & \multicolumn{2}{|c|}{5,611} & \multicolumn{2}{|c|}{5.860} & \multicolumn{2}{|c|}{5,611} & \multicolumn{2}{|c|}{5,860} \\
\hline$R^{2}$ & \multicolumn{2}{|c|}{0.2227} & \multicolumn{2}{|c|}{0.1958} & \multicolumn{2}{|c|}{0.4156} & \multicolumn{2}{|c|}{0.4054} & \multicolumn{2}{|c|}{0.2991} & \multicolumn{2}{|c|}{0.3408} \\
\hline$\chi^{2}$ & \multicolumn{2}{|c|}{$1,697.1 * *$} & \multicolumn{2}{|c|}{$1,869.68 * *$} & \multicolumn{2}{|c|}{$4,104.24 * *$} & \multicolumn{2}{|c|}{$4,072.47 * *$} & \multicolumn{2}{|c|}{$2,597.83^{* *}$} & \multicolumn{2}{|c|}{$3.187 .55^{* *}$} \\
\hline
\end{tabular}

measuring the frequency of parents reading to their children, which enters the measure of parental effort.

The school characteristics we use are its size, measured by the $\log$ of the number of pupils, and its type: state or private at ages 7,11 , and 16 ; and single-sex, comprehensive (the reference value in the tables), secondary modern, or grammar at age $16 .{ }^{19}$ We also include several measures of class size, at the three different ages, and their square, to capture possible nonlinearities in class size.

An important aspect of a school's quality is the peer group effect, that is, the characteristics of its students. ${ }^{20}$ To capture this, we consider both academic and social indicators: the percentage of boys and girls in the school attended at age 16 who were studying for O-levels, whether pupils from the school attended subsequently enrolled into higher education (both indicate a more academic peer group), and the proportion of classmates whose father has a nonmanual occupation.

The final rows of table 2 report some geographical characteristics. As well as regional dummies, we include the proportion of comprehensive schools in the area and some social indicators of the enumeration district (a small geographical area comprising around 200 households) where the child was living at age 16. These variables are taken from the 1971 census, and correspond to those used by Dearden, Ferri, and Meghir (2002).

Dummies for missing values are used for each of the variables to capture possible nonrandomness in nonresponse. $^{21}$

\footnotetext{
19 These were the three most common types of state schools in the 1970s Grammar schools admitted pupils in the top quartile of the distribution of an exam taken at the age of 11 (the eleven-plus). The rest of the students went to secondary modern schools. The system was gradually reformed. Secondary modern and (most) grammar schools were replaced by comprehensive schools, which did not select by ability.

${ }^{20}$ This is a well-documented phenomenon; see Moreland and Levine (1992) for a survey from a psychology/education viewpoint, Summers and Wolfe (1977), Henderson, Mieszkowski, and Sauvageau (1978) for early economic empirical studies, and Epple, Romano, and Sieg (2003), an Zimmer and Toma (2000) for more recent ones. The theoretical analyses of Arnott and Rowse (1987) and de Bartolome (1990) were among the first to take the peer group effect explicitly into account.

${ }^{21}$ These are the unlabeled variables in the table, after each variable or group of variables; for example, the 0.089 in the line below "weight at
}

\section{Results}

Table 3 reports our 3SLS estimates of equations (10) to (12). In each of the three effort equations, the effort level exerted by the other two groups of agents is significant, with the exception of parental effort on the school effort and the school effort on parental effort. This confirms our assumption of simultaneous endogenous determination of effort levels as a Nash equilibrium. Also note that a 0 coefficient does not necessarily falsify the Nash equilibrium hypothesis, because the intersection of the relevant best-reply functions could happen close to a stationary point of one of them (as, for example, at point $E_{1}$ in panel a in figure 1). We have also tested, and found support for, the hypothesis that girls and boys differ significantly, and therefore we report all our results for the two separate samples. ${ }^{22}$

Table 3 suggests that parental and the child's efforts are strategic complements: by exerting more effort, parents induce their child to exert more effort, and, vice versa, parents respond positively to their children's exerting more effort. In other words, there is a multiplier effect, suggesting, for example, that policies aimed at affecting directly the effort exerted by children and parents may prove very effective. On the other hand, the role of the school effort is less clear-cut: it affects negatively the effort exerted by children but not that exerted by parents. Conversely, schools respond positively to children's effort but not to parents' effort.

A noteworthy feature of the children's effort equation is the paucity of statistically significant explanatory variables: only the other effort levels, their own ability and birth

birth" indicates that $8.9 \%$ of the observations in the sample did not report the value of this variable. All estimations include these dummy variables, but we do not report their coefficients to make the reading of the tables easier.

${ }^{22}$ We did so by estimating a more general specification of the entire model with a gender dummy interacting with each of the explanatory variables, and testing the joint statistical significance of the parameters of these interaction terms in the educational attainment equation, using a likelihood-ratio test. The test statistic for this test is $\chi^{2}(88)=288.02$ ( $p$-value 0.0000). We prefer to report separate samples, rather than the more general model with the interaction terms, because its very large number of explanatory variables would make the interpretation of the coefficients very cumbersome. 
weight, and, for boys only, their household total income and their socioeconomic peer group seem to affect children's effort. Clearly, our results are tentative, constrained by the limitations of the data set, but a possible interpretation for this finding is that children from different backgrounds do not differ significantly in their propensity to exert effort. If confirmed by more targeted studies, this may have policy implications for the types of incentives to provide to pupils in schools.

The parents' effort equation indicates that the presence of siblings reduces parental effort. This is an interesting result, which also suggests that the variables we have used to measure effort do indeed capture relevant features of parental effort. At the theoretical level, parents may face a trade-off between the number of their children and the attention each of them receives (Becker, 1960; Hanushek, 1992). Parental taste for education, as reflected by their education and the frequency of their reading, does positively influence their own effort. There is also some indication that the mother's position in the labor market may have some effect on parental effort, but possibly in unexpected ways. The percentage of household income not earned by the father figure has a clear negative influence on parents' effort, and the effect of the mother being in work is negative when the child is 7 and positive when the child is 16 , at least for boys. Household income and socioeconomic status, on the other hand, affect parental effort positively; measures of deprivation (financial hardship and receiving free school meals) affect it negatively. The peer group of their child appears to affect the effort of boys' parents more than it does girls' parents.

The school's effort is affected mainly by schoolwide variables. Consider the composition of the child's socioeconomic peer group, that is, the proportion of classmates whose father has high socioeconomic status. Seen from the school's viewpoint, this is the social background of its pupils, and, naturally, it affects positively the school's effort: schools that have a larger proportion of children from higher socioeconomic groups work harder. Individual parents' education and income, on the other hand, do not affect the school's effort. School's effort is also higher in larger schools at age 16. Conversely, it increases with class size at age 7 and at age 11; at age 16, it increases with class size up to around 25 , though the coefficients are not statistically significant for girls in math. ${ }^{23}$ The increase in effort with class size may provide an explanation for the "wrong" sign of the relationship between class size and achievement, which is often found in studies that use this data set (Levacic \& Vignoles, 2002). With regard to the school type variables, the single-sex variable has a negative coefficient. Private schools exert an effort level not significantly different from state schools (except, at most, for boys at age 16), and secondary modern schools exert less effort than com-

\footnotetext{
${ }^{23}$ The maxima along the class size axis are 25.49 for girls in English and 24.23 and 25.75 for boys in English and math, respectively.
}

prehensive schools, in line with the perception of the British educational system at the time.

Table 5 presents the results for our ordered probit estimates of equation (17). To ascertain whether effort is endogenously determined together with qualification, we perform the DWH test described in section IV on the parameters of equation (16). We can reject, at conventional significance levels, the null hypothesis that the residuals of the effort equations do not affect examination results for the sample of girls, but not for the sample of boys. ${ }^{24}$ We prefer to apply the same procedures to both samples, and therefore, in table 5, we present the estimation of the education production function using both the predicted values from the 3SLS system, on the left-hand side of the table, and the original effort variables, on the right-hand side. The effort variables are similar in sign but different in size, and the effects of many of the other variables are instead broadly similar, suggesting a degree of robustness.

As we expect, effort strongly improves educational attainment, as shown by the first three rows: the interaction terms among effort levels are not significant. On the other hand, parents' effort and child's ability are complements, whereas school's effort and child's ability are substitutes in the education production function. Table 5 also shows that children's ability has, as one would expect, a strong independent, positive effect on their examination results. Being in a private school at age 16 (at age 11) affects positively (negatively) the results for boys but not for girls, and a secondary modern affects positively boys' results. Family composition appears to matter only for girls, whereas the academic peer group affects attainment only for boys, if at all. This is consistent with the view that boys are affected by peers, girls by siblings. Of the census variables listed in table 2, we report in table 5 only those that are statistically significant for at least one subsample: the percentage of unemployed or sick, the proportion of owner-occupied houses, the proportion of council tenants, and the average number of persons per room in the census enumeration district. These variables have a negative effect on examination results. With regard to regional dummies, the reference group is London, which appears to have a direct negative effect on results.

Table 6 shows that the effect of effort is robust to different measures of ability. It compares the uppermost part of table 5 (on the left-hand side of table 6) with the coefficients obtained by replacing the measure of ability used above (obtained from the results of the questionnaire at all the three ages) with the equivalent measure using only the results of the tests administered at age 7, both with the predicted (first two columns) and the original (last two columns) effort variables. As table 6 shows, there is no qualitative difference between the two measures of ability.

${ }^{24}$ The test statistics of the likelihood-ratio tests of the null hypothesis are $\chi^{2}(3)=12.16(p$-value 0.0068$)$ for the sample of girls, $\chi^{2}(3)=4.75$ ( $p$-value 0.1908 ) for the sample of boys. 
Table 5.-Ordered Probit Estimates of Exam Results Equation

\begin{tabular}{|c|c|c|c|c|c|c|c|c|}
\hline \multirow[b]{3}{*}{ Variable } & \multicolumn{4}{|c|}{ Using Predicted Effort Variables } & \multicolumn{4}{|c|}{ Using Original Effort Variables } \\
\hline & \multicolumn{2}{|c|}{ Girls } & \multicolumn{2}{|c|}{ Boys } & \multicolumn{2}{|c|}{ Girls } & \multicolumn{2}{|c|}{ Boys } \\
\hline & Coef. & s.e. & Coef. & s.e. & Coef. & s.e. & Coef. & s.e. \\
\hline Child's effort & $0.260 * *$ & 0.046 & $0.209 * *$ & 0.038 & $0.644 * *$ & 0.022 & $0.715^{* *}$ & 0.023 \\
\hline Parents' effort & $1.525 * *$ & 0.073 & $1.758 * *$ & 0.071 & $0.239 * *$ & 0.026 & $0.191 * *$ & 0.025 \\
\hline School's effort & $0.307 * *$ & 0.076 & $0.391 * *$ & 0.069 & $0.054 *$ & 0.024 & $0.087 * *$ & 0.025 \\
\hline \multicolumn{9}{|l|}{ Child characteristics } \\
\hline Ability & $0.308 * *$ & 0.013 & $0.276 * *$ & 0.012 & $0.425 * *$ & 0.012 & $0.390 * *$ & 0.011 \\
\hline \multicolumn{9}{|l|}{ Interaction terms } \\
\hline Child's $\times$ parents' effort & -0.084 & 0.089 & -0.037 & 0.087 & -0.020 & 0.029 & -0.003 & 0.030 \\
\hline Child's $\times$ schools' effort & 0.114 & 0.101 & -0.081 & 0.094 & 0.002 & 0.029 & -0.025 & 0.027 \\
\hline Parents' $\times$ schools' effort & -0.068 & 0.103 & -0.159 & 0.103 & -0.051 & 0.033 & -0.048 & 0.034 \\
\hline Child's $\times$ parents' $\times$ schools' effort & 0.210 & 0.124 & -0.025 & 0.121 & $0.075^{*}$ & 0.035 & 0.049 & 0.042 \\
\hline Child effort $\times$ ability & 0.029 & 0.022 & 0.034 & 0.019 & $0.105 * *$ & 0.011 & $0.089 * *$ & 0.011 \\
\hline Parents' effort $\times$ ability & $0.113^{* *}$ & 0.023 & $0.130 * *$ & 0.021 & 0.013 & 0.011 & 0.022 & 0.011 \\
\hline School's effort $\times$ ability & $-0.079 * *$ & 0.024 & $-0.079 * *$ & 0.025 & $-0.047 * *$ & 0.011 & $-0.046^{* *}$ & 0.012 \\
\hline \multicolumn{9}{|l|}{ Family characteristics } \\
\hline Older brothers & $0.075^{* *} *$ & 0.021 & 0.032 & 0.020 & 0.019 & 0.021 & -0.020 & 0.020 \\
\hline Younger brothers & $0.088 * *$ & 0.020 & -0.031 & 0.019 & $0.048^{*}$ & 0.020 & $-0.045^{*}$ & 0.019 \\
\hline Older sisters & $0.063 * *$ & 0.021 & $0.041 *$ & 0.020 & -0.020 & 0.020 & -0.038 & 0.020 \\
\hline Younger sisters & 0.022 & 0.020 & $0.052 *$ & 0.022 & -0.035 & 0.020 & -0.004 & 0.021 \\
\hline Mother in work age 16 & -0.042 & 0.038 & $-0.098 * *$ & 0.038 & -0.032 & 0.038 & -0.024 & 0.038 \\
\hline Mother in work age 7 & 0.055 & 0.036 & 0.045 & 0.036 & -0.030 & 0.035 & -0.043 & 0.035 \\
\hline Mother married at birth & 0.018 & 0.091 & 0.130 & 0.072 & 0.069 & 0.091 & $0.174 *$ & 0.073 \\
\hline Houseowner & -0.061 & 0.041 & $-0.197 * *$ & 0.040 & $0.116^{* *}$ & 0.040 & 0.045 & 0.038 \\
\hline Total household income ( $£$ per & & & & & & & & \\
\hline week) & -0.001 & 0.001 & -0.001 & 0.001 & 0.001 & 0.001 & 0.002 & 0.001 \\
\hline$\%$ of income not from father & $0.159 *$ & 0.063 & 0.056 & 0.062 & 0.088 & 0.062 & $-0.126^{*}$ & 0.061 \\
\hline Free school meals in school age 11 & -0.061 & 0.063 & $0.170 *$ & 0.068 & $-0.213^{* *}$ & 0.062 & -0.139 & 0.066 \\
\hline Financial hardship at 11 & 0.062 & 0.055 & 0.099 & 0.056 & -0.094 & 0.054 & 0.009 & 0.056 \\
\hline Father has higher education & -0.003 & 0.070 & 0.087 & 0.065 & $0.141 *$ & 0.070 & $0.173 * *$ & 0.064 \\
\hline Father has secondary education & -0.021 & 0.040 & -0.058 & 0.040 & 0.006 & 0.040 & 0.026 & 0.040 \\
\hline Mother has higher education & 0.055 & 0.083 & -0.137 & 0.085 & $0.261 * *$ & 0.082 & 0.098 & 0.084 \\
\hline Mother has secondary education & $-0.133 * *$ & 0.039 & 0.000 & 0.038 & -0.022 & 0.039 & 0.001 & 0.038 \\
\hline Father reads books regularly & $-0.258 * *$ & 0.043 & $-0.256^{* *}$ & 0.043 & 0.016 & 0.041 & 0.034 & 0.041 \\
\hline Father reads books occasionally & $-0.207 * *$ & 0.046 & -0.044 & 0.049 & -0.027 & 0.046 & 0.086 & 0.048 \\
\hline Mother reads books regularly & -0.074 & 0.041 & $-0.211 * *$ & 0.040 & 0.063 & 0.040 & 0.018 & 0.039 \\
\hline Mother reads books occasionally & -0.059 & 0.043 & $-0.172 * *$ & 0.043 & 0.021 & 0.043 & -0.027 & 0.043 \\
\hline School characteristics & & & & & & & & \\
\hline English class size age 16 & 0.028 & 0.019 & -0.012 & 0.018 & $0.041 *$ & 0.018 & 0.006 & 0.018 \\
\hline$(\text { English class size age } 16)^{2}$ & 0.000 & 0.000 & 0.001 & 0.000 & $-0.001^{*}$ & 0.000 & 0.000 & 0.000 \\
\hline Math class size age 16 & -0.001 & 0.016 & -0.006 & 0.017 & 0.001 & 0.016 & 0.003 & 0.016 \\
\hline$(\text { Math class size age } 16)^{2}$ & 0.000 & 0.000 & 0.000 & 0.000 & 0.000 & 0.000 & 0.000 & 0.000 \\
\hline No. children in child's class age 7 & -0.013 & 0.014 & -0.015 & 0.012 & -0.009 & 0.014 & -0.012 & 0.011 \\
\hline$(\text { No. children in child's class age } 7)^{2}$ & 0.000 & 0.000 & 0.000 & 0.000 & 0.000 & 0.000 & 0.000 & 0.000 \\
\hline No. children in child's class age 11 & 0.000 & 0.011 & -0.008 & 0.009 & 0.004 & 0.011 & -0.006 & 0.009 \\
\hline (No. children in child's class age & & & & & & & & \\
\hline 11$)^{2}$ & 0.000 & 0.000 & 0.000 & 0.000 & 0.000 & 0.000 & 0.000 & 0.000 \\
\hline Single-sex school age 16 & 0.078 & 0.098 & -0.030 & 0.075 & 0.114 & 0.093 & -0.077 & 0.075 \\
\hline Grammar school age 16 & -0.055 & 0.062 & 0.112 & 0.064 & -0.018 & 0.060 & 0.038 & 0.063 \\
\hline Secondary modern age 16 & 0.053 & 0.046 & $0.119 * *$ & 0.046 & -0.072 & 0.045 & 0.022 & 0.045 \\
\hline Private school age 16 & -0.135 & 0.123 & $0.431 * *$ & 0.108 & -0.061 & 0.116 & $0.472 * *$ & 0.106 \\
\hline Private school age 11 & 0.089 & 0.109 & $-0.304 * *$ & 0.107 & -0.001 & 0.110 & -0.029 & 0.108 \\
\hline Private school age 7 & $-0.295^{*}$ & 0.120 & -0.097 & 0.107 & -0.190 & 0.119 & -0.145 & 0.104 \\
\hline Peer group characteristics & & & & & & & & \\
\hline Pupils from school go to university & -0.075 & 0.043 & $0.048 *$ & 0.043 & 0.051 & 0.041 & $0.118 * *$ & 0.040 \\
\hline$\%$ of girls studying for O-levels & 0.002 & 0.001 & 0.000 & 0.001 & $0.003 * *$ & 0.001 & -0.001 & 0.001 \\
\hline$\%$ of boys studying for O-levels & 0.002 & 0.001 & $0.002 *$ & 0.001 & 0.001 & 0.001 & $0.004 * *$ & 0.001 \\
\hline $10 \%-19 \%$ of classmates have & & & & & & & & \\
\hline nonmanual father & 0.042 & 0.067 & -0.100 & 0.065 & 0.114 & 0.066 & 0.040 & 0.064 \\
\hline $20 \%-29 \%$ of classmates have & & & & & & & & \\
\hline nonmanual father & -0.038 & 0.066 & $-0.129 *$ & 0.065 & 0.108 & 0.065 & 0.085 & 0.063 \\
\hline $30 \%-39 \%$ of classmates have & & & & & & & & \\
\hline nonmanual father & 0.010 & 0.072 & -0.132 & 0.069 & 0.109 & 0.071 & 0.103 & 0.067 \\
\hline $40 \%-49 \%$ of classmates have & & & & & & & & \\
\hline nonmanual father & 0.089 & 0.080 & -0.140 & 0.076 & $0.184 *$ & 0.077 & 0.134 & 0.072 \\
\hline $50 \%-59 \%$ of classmates have & & & & & & & & \\
\hline nonmanual father & 0.119 & 0.080 & -0.139 & 0.082 & $0.195 *$ & 0.077 & 0.107 & 0.077 \\
\hline $60 \%-69 \%$ of classmates have & & & & & & & & \\
\hline nonmanual father & -0.044 & 0.086 & -0.142 & 0.084 & 0.154 & 0.085 & $0.185^{*}$ & 0.082 \\
\hline
\end{tabular}


TABLE 5.-(CONTINUED)

\begin{tabular}{|c|c|c|c|c|c|c|c|c|}
\hline \multirow[b]{3}{*}{ Variable } & \multicolumn{4}{|c|}{ Using Predicted Effort Variables } & \multicolumn{4}{|c|}{ Using Original Effort Variables } \\
\hline & \multicolumn{2}{|c|}{ Girls } & \multicolumn{2}{|c|}{ Boys } & \multicolumn{2}{|c|}{ Girls } & \multicolumn{2}{|c|}{ Boys } \\
\hline & Coef. & s.e. & Coef. & s.e. & Coef. & s.e. & Coef. & s.e. \\
\hline \multicolumn{9}{|l|}{$70 \%-79 \%$ of classmates have } \\
\hline $\begin{array}{l}80 \%-100 \% \text { of classmates have } \\
\text { nonmanual father }\end{array}$ & $0.352 * *$ & 0.095 & 0.045 & 0.102 & $0.462 * *$ & 0.094 & $0.373 * *$ & 0.099 \\
\hline \multicolumn{9}{|l|}{ Geographical characteristics } \\
\hline$\%$ of unemployed or sick ${ }^{\mathrm{a}}$ & $-0.009 * *$ & 0.003 & -0.002 & 0.003 & $-0.008^{*}$ & 0.003 & -0.003 & 0.003 \\
\hline$\%$ of owner occupied households ${ }^{a}$ & -0.002 & 0.001 & $-0.003 * *$ & 0.001 & -0.002 & 0.001 & $-0.004^{* *}$ & 0.001 \\
\hline$\%$ of council tenants ${ }^{\mathrm{a}}$ & -0.001 & 0.001 & $-0.002 *$ & 0.001 & -0.001 & 0.001 & $-0.002 *$ & 0.001 \\
\hline Average no. persons per room ${ }^{\mathrm{a}}$ & -0.136 & 0.195 & $-0.421 *$ & 0.185 & -0.145 & 0.195 & $-0.485^{* *}$ & 0.186 \\
\hline Northwest age 11 & 0.036 & 0.060 & $0.157 *$ & 0.063 & 0.037 & 0.059 & 0.076 & 0.064 \\
\hline North age 11 & $0.354 * *$ & 0.079 & $0.493 * *$ & 0.077 & 0.136 & 0.074 & $0.215^{* *}$ & 0.074 \\
\hline East and West Riding age 11 & $0.278 * *$ & 0.068 & $0.342 * *$ & 0.063 & $0.176^{* *}$ & 0.067 & $0.187^{* *} *$ & 0.063 \\
\hline North Midlands age 11 & $0.213^{* *}$ & 0.068 & $0.272 * *$ & 0.065 & 0.083 & 0.067 & $0.128 *$ & 0.064 \\
\hline Eastern age 11 & $0.147 *$ & 0.064 & $0.195 * *$ & 0.061 & 0.086 & 0.063 & 0.094 & 0.061 \\
\hline Southwest age 11 & 0.118 & 0.064 & $0.212 * *$ & 0.067 & 0.102 & 0.064 & 0.081 & 0.068 \\
\hline Midlands age 11 & $0.346^{* *}$ & 0.062 & $0.253 * *$ & 0.063 & $0.264 * *$ & 0.061 & 0.103 & 0.062 \\
\hline Wales age 11 & $0.315 * *$ & 0.089 & 0.139 & 0.081 & 0.083 & 0.087 & -0.102 & 0.078 \\
\hline Scotland age 11 & $0.613^{* *}$ & 0.094 & $0.851 * *$ & 0.095 & $0.204 *$ & 0.088 & $0.262 * *$ & 0.089 \\
\hline$\%$ of comprehensive schools in LEA & -0.054 & 0.072 & -0.130 & 0.071 & -0.095 & 0.072 & -0.060 & 0.071 \\
\hline$\mu_{1}:$ boundary between $\mathrm{Q} 0$ and $\mathrm{Q} 1$ & -1.595 & 0.445 & -2.563 & 0.445 & -1.013 & 0.425 & -1.756 & 0.413 \\
\hline$\mu_{2}$ : boundary between Q1 and Q2 & -1.092 & 0.445 & -2.044 & 0.445 & -0.502 & 0.425 & -1.228 & 0.413 \\
\hline$\mu_{3}$ : boundary between Q2 and Q3 & -0.573 & 0.445 & -1.602 & 0.445 & 0.026 & 0.424 & -0.779 & 0.413 \\
\hline$\mu_{4}$ : boundary between Q3 and Q4 & 0.062 & 0.445 & -0.883 & 0.445 & 0.669 & 0.424 & -0.049 & 0.413 \\
\hline$\mu_{5}$ : boundary between Q4 and Q5 & 1.528 & 0.445 & 0.431 & 0.445 & 2.173 & 0.425 & 1.297 & 0.413 \\
\hline$\mu_{6}$ : boundary between Q5 and Q6 & 1.947 & 0.446 & 0.737 & 0.446 & 2.602 & 0.425 & 1.610 & 0.414 \\
\hline$\mu_{7}$ : boundary between Q6 and Q7 & 2.304 & 0.446 & 1.053 & 0.446 & 2.969 & 0.425 & 1.934 & 0.415 \\
\hline$\mu_{8}$ : boundary between Q7 and Q8 & 2.593 & 0.446 & 1.326 & 0.447 & 3.265 & 0.425 & 2.214 & 0.415 \\
\hline$\mu_{9}$ : boundary between Q8 and Q9 & 3.052 & 0.447 & 1.759 & 0.448 & 3.731 & 0.426 & 2.653 & 0.416 \\
\hline$\mu_{10}$ : boundary between Q9 and Q10 & 3.671 & 0.448 & 2.350 & 0.450 & 4.357 & 0.427 & 3.246 & 0.418 \\
\hline Number of observations & \multicolumn{2}{|c|}{5,611} & \multicolumn{2}{|c|}{5,860} & \multicolumn{2}{|c|}{5,611} & \multicolumn{2}{|c|}{5,860} \\
\hline Pseudo $R^{2}$ & \multicolumn{2}{|c|}{0.2749} & \multicolumn{2}{|c|}{0.2747} & \multicolumn{2}{|c|}{0.2825} & \multicolumn{2}{|c|}{0.2815} \\
\hline Wald $\chi^{2}(90)$ & \multicolumn{2}{|c|}{$4,343.33 * *$} & \multicolumn{2}{|c|}{$4,605.62^{* *}$} & \multicolumn{2}{|c|}{$4,337.91 * *$} & \multicolumn{2}{|c|}{$4,670.67 * *$} \\
\hline Log likelihood & \multicolumn{2}{|c|}{$-8,857.53$} & \multicolumn{2}{|c|}{$-9,222.91$} & \multicolumn{2}{|c|}{$-8,764.69$} & \multicolumn{2}{|c|}{$-9,136.21$} \\
\hline
\end{tabular}

aEnumeration district-level variable from 1971 Census Small Area Statistics. Other variables included in the model and not reported are: father's socioeconomic status unclassifiable, other census variables, an other regional dummies. *Significant at the $5 \%$ level. **Significant at the $1 \%$ level.

Table 7 quantifies these findings in more detail, reporting the marginal effects of changes in effort on examination outcomes derived from the ordered probit estimation. The values in each column are the marginal changes in the probability of the eleven possible outcomes due to a marginal change in effort of the various agents, evaluated at the sample means for all variables. The table suggests that for both girls and boys, the parents' effort is the most effective in affecting educational outcomes. This is in line with Carneiro and Heckman's findings that "a major determinant of successful schools is successful families. Schools work with what parents bring them. They operate more effectively if parents reinforce them by encouraging and motivating children" (Carneiro \& Heckman, 2005, p. 18).

Table 7 is presented graphically in figure 4 . An increase in effort pushes the mean ability children into the group of

Table 6.-Ordered Probit Estimates of Exam Results Equation with Ability 7 Only

\begin{tabular}{|c|c|c|c|c|c|c|c|c|}
\hline \multirow[b]{3}{*}{ Variable } & \multicolumn{4}{|c|}{ Using Predicted Effort Variables } & \multicolumn{4}{|c|}{ Using Original Effort Variables } \\
\hline & \multicolumn{2}{|c|}{ Girls } & \multicolumn{2}{|c|}{ Boys } & \multicolumn{2}{|c|}{ Girls } & \multicolumn{2}{|c|}{ Boys } \\
\hline & Coef. & s.e. & Coef & s.e. & Coef. & s.e. & Coef. & s.e. \\
\hline Child's effort & $0.421 * *$ & 0.037 & $0.290 * *$ & 0.033 & $0.689 * *$ & 0.021 & $0.782 * *$ & 0.022 \\
\hline Parents' effort & $1.415^{* *}$ & 0.051 & $1.625 * *$ & 0.049 & $0.370 * *$ & 0.025 & $0.294 * *$ & 0.024 \\
\hline School's effort & $0.293 * *$ & 0.074 & $0.302 * *$ & 0.067 & $0.102 * *$ & 0.024 & $0.125 * *$ & 0.025 \\
\hline Ability & $0.245^{* *}$ & 0.020 & $0.244 * *$ & 0.019 & $0.376^{* *}$ & 0.019 & $0.375^{* *}$ & 0.019 \\
\hline Child's $\times$ parents' effort & 0.073 & 0.059 & $0.122 *$ & 0.060 & $0.071 * *$ & 0.026 & $0.091 * *$ & 0.027 \\
\hline Child's $\times$ schools' effort & 0.049 & 0.082 & -0.028 & 0.077 & -0.017 & 0.027 & -0.038 & 0.028 \\
\hline Parents' $\times$ schools' effort & -0.032 & 0.081 & -0.136 & 0.082 & $-0.076^{*}$ & 0.030 & -0.060 & 0.033 \\
\hline Child's $\times$ parents' $\times$ schools' effort & 0.133 & 0.113 & -0.076 & 0.107 & 0.060 & 0.035 & 0.026 & 0.041 \\
\hline Child's effort $\times$ ability & -0.005 & 0.039 & 0.021 & 0.034 & $0.133 * *$ & 0.022 & $0.098 * *$ & 0.023 \\
\hline Parents' effort $\times$ ability & $0.118 * *$ & 0.039 & $0.145 * *$ & 0.037 & -0.011 & 0.024 & 0.024 & 0.024 \\
\hline School's effort $\times$ ability & -0.052 & 0.037 & $-0.193 * *$ & 0.041 & $-0.061 * *$ & 0.021 & $-0.099 * *$ & 0.024 \\
\hline
\end{tabular}

*Significant at the $5 \%$ level. **Significant at the $1 \%$ level. 
Table 7.-Marginal Effects

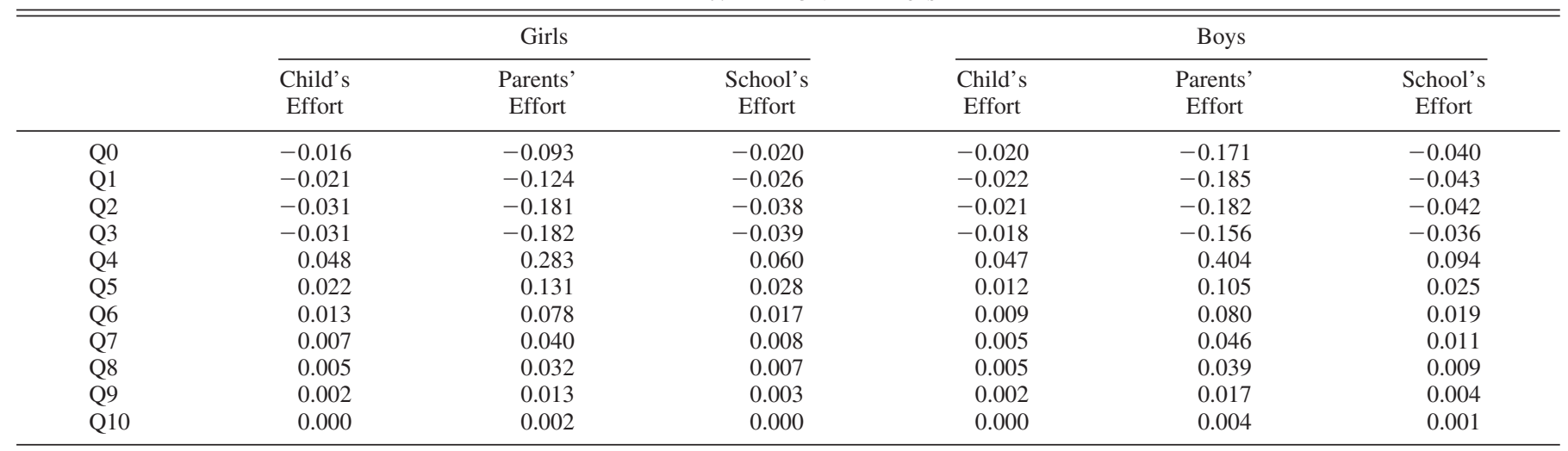

individuals who have at least one to four O-levels. Clearly it is premature to draw policy prescription from our estimates, but these results would suggest that policies aimed at improving parental effort directly may be an effective way of influencing children's educational attainment.

\section{Decomposing the Influence on Attainment}

Table 5 shows that family background variables, such as income indicators, parents' education, and their taste for reading have a less definite effect than they had on effort, and they appear to have a weaker influence than much of the literature suggests (Ermisch \& Francesconi, 2001; Dearden et al., 2002). The results are similar for income variables, which are not statistically significant either. Given two children who exert the same effort and whose parents and schools also exert the same effort, they will not obtain different qualifications purely because their fathers have different levels of education or their households different incomes. This has, in our view, a natural interpretation: family social background and income influence school achievement indirectly, via parental effort, rather than directly. This is unlike other variables, such as ability, which instead influence achievement both directly and indirectly via effort: given two children who exert the same effort, the abler obtains a higher school qualification. The two effects, direct and indirect, can be separated empirically in a natural way, thanks to the theoretical model developed in section
II. ${ }^{25}$ Recall that the probability that a child obtains qualification $k$ is given in equation (2) by $\pi_{k}(\cdot)$. At the Nash equilibrium, $e^{C}, e^{P}$, and $e^{S}$ are themselves functions of the control variables, and we therefore write $\pi_{k}(\cdot)$ as $\pi_{k}\left(e^{C}(\cdot)\right.$, $\left.a ; e^{P}(\cdot), s^{P} ; e^{S}(\cdot), s^{S}\right)$, where the (.) includes all the variables in the corresponding column in table 2 . A change in one of these variables, say $x$, causes a change in $\pi_{k}(\cdot)$ given by ${ }^{26}$

$$
\begin{aligned}
\frac{d \pi_{k}(\cdot)}{d x}= & \frac{\partial \pi_{k}(\cdot)}{\partial e^{C}} \frac{\partial e^{C}(\cdot)}{\partial x}+\frac{\partial \pi_{k}(\cdot)}{\partial e^{P}} \frac{\partial e^{P}(\cdot)}{\partial x} \\
& +\frac{\partial \pi_{k}(\cdot)}{\partial e^{S}} \frac{\partial e^{S}(\cdot)}{\partial x}+\frac{\partial \pi_{k}(\cdot)}{\partial x} .
\end{aligned}
$$

In equation (18), the first three terms on the right-hand side measure the indirect effect of a change in variable $x$ on qualification via the child's, the parents', and the school's effort, respectively, whereas the last term on that side measures the direct effect of the variable $x$ on qualification, that is, the change in the probability of qualification $i$ for a

$25 \mathrm{We}$ are grateful to a referee for suggestions that have led to this section.

${ }^{26}$ Note the symbol $d$ on the left-hand side, denoting the total effect of a change $d x$ in variable $x$, and the symbol $\partial$ on the last term on the right-hand side, denoting the direct effect of a change in $x$ only, that is, the effects that a change in $x$ would have on the probability $\pi_{k}$ while keeping the values of the effort constant.

Figure 4.-Changes in Probabilities of Qualification, Q0-Q10
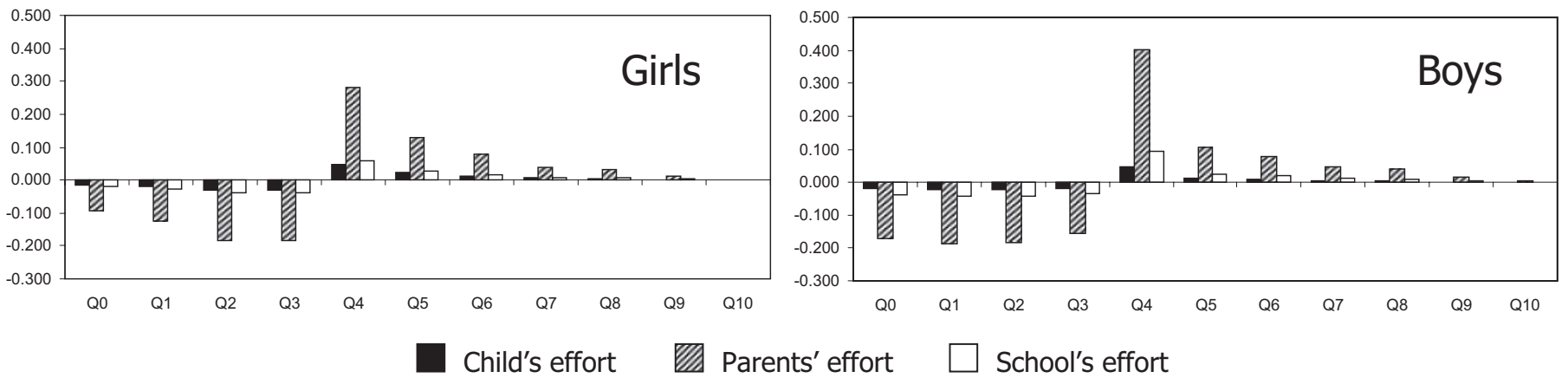
Table 8.-Decomposition of Marginal EfFects

\begin{tabular}{|c|c|c|c|c|c|c|c|c|c|c|}
\hline$[1]$ & $\begin{array}{c}{[2]} \\
\frac{\partial \pi_{k}(\cdot)}{\partial e^{C}}\end{array}$ & $\begin{array}{c}{[3]} \\
\frac{\partial e^{C}(\cdot)}{\partial x}\end{array}$ & $\begin{array}{c}{[4]} \\
\frac{\partial \pi_{k}(\cdot)}{\partial e^{P}}\end{array}$ & $\begin{array}{c}{[5]} \\
\frac{\partial e^{P}(\cdot)}{\partial x}\end{array}$ & $\begin{array}{c}\text { [6] } \\
\frac{\partial \pi_{k}(\cdot)}{\partial e^{S}}\end{array}$ & $\begin{array}{c}{[7]} \\
\frac{\partial e^{S}(\cdot)}{\partial x}\end{array}$ & $\begin{array}{c}{[8]} \\
\frac{\partial \pi_{k}(\cdot)}{\partial x}\end{array}$ & $\begin{array}{c}\text { [9] } \\
\frac{d \pi_{k}(\cdot)}{d x}\end{array}$ & $\frac{d \tilde{\pi}_{k}(\cdot)}{d x} / \frac{d 10]}{d x}$ & $\begin{array}{c}{[11]} \\
\frac{d \tilde{\pi}_{k}(\cdot)}{d x}\end{array}$ \\
\hline \multicolumn{11}{|c|}{ Ability_Girls } \\
\hline Q0 & -0.016 & \multirow{11}{*}{0.139} & -0.093 & \multirow{11}{*}{0.115} & -0.020 & \multirow{11}{*}{0.029} & -0.019 & -0.033 & 1.282 & -0.042 \\
\hline Q1 & -0.021 & & -0.124 & & -0.026 & & -0.025 & -0.043 & 1.009 & -0.044 \\
\hline $\mathrm{Q} 2$ & -0.031 & & -0.181 & & -0.038 & & -0.037 & -0.063 & 0.850 & -0.054 \\
\hline Q3 & -0.031 & & -0.182 & & -0.039 & & -0.037 & -0.063 & 0.734 & -0.047 \\
\hline $\mathrm{Q} 4$ & 0.048 & & 0.283 & & 0.060 & & 0.058 & 0.099 & 0.816 & 0.081 \\
\hline Q5 & 0.022 & & 0.131 & & 0.028 & & 0.027 & 0.046 & 0.843 & 0.039 \\
\hline Q6 & 0.013 & & 0.078 & & 0.017 & & 0.016 & 0.027 & 0.961 & 0.026 \\
\hline Q7 & 0.007 & & 0.040 & & 0.008 & & 0.008 & 0.014 & 1.103 & 0.015 \\
\hline Q8 & 0.005 & & 0.032 & & 0.007 & & 0.007 & 0.011 & 1.312 & 0.015 \\
\hline Q9 & 0.002 & & 0.013 & & 0.003 & & 0.003 & 0.004 & 1.744 & 0.008 \\
\hline Q10 & 0.000 & & 0.002 & & 0.000 & & 0.000 & 0.001 & 2.771 & 0.002 \\
\hline \multicolumn{11}{|c|}{ Father reads books regularly_-Girls } \\
\hline Q0 & -0.016 & \multirow{11}{*}{0.064} & -0.093 & \multirow{11}{*}{0.205} & -0.020 & \multirow{11}{*}{0.024} & 0.017 & -0.004 & 1.882 & -0.007 \\
\hline $\mathrm{Q} 1$ & -0.021 & & -0.124 & & -0.026 & & 0.022 & -0.006 & 1.348 & -0.008 \\
\hline Q2 & -0.031 & & -0.181 & & -0.038 & & 0.031 & -0.009 & 1.069 & -0.010 \\
\hline Q3 & -0.031 & & -0.182 & & -0.039 & & 0.030 & -0.010 & 0.846 & -0.008 \\
\hline Q4 & 0.048 & & 0.283 & & 0.060 & & -0.050 & 0.013 & 1.115 & 0.014 \\
\hline Q5 & 0.022 & & 0.131 & & 0.028 & & -0.022 & 0.007 & 1.008 & 0.007 \\
\hline Q6 & 0.013 & & 0.078 & & 0.017 & & -0.013 & 0.004 & 1.128 & 0.005 \\
\hline Q7 & 0.007 & & 0.040 & & 0.008 & & -0.007 & 0.002 & 1.281 & 0.003 \\
\hline Q8 & 0.005 & & 0.032 & & 0.007 & & -0.005 & 0.002 & 1.512 & 0.003 \\
\hline Q9 & 0.002 & & 0.013 & & 0.003 & & -0.002 & 0.001 & 1.999 & 0.001 \\
\hline Q10 & 0.000 & & 0.002 & & 0.000 & & 0.000 & 0.000 & 3.179 & 0.000 \\
\hline \multicolumn{11}{|c|}{ Ability-Boys } \\
\hline Q0 & -0.020 & \multirow{11}{*}{0.145} & -0.171 & \multirow{11}{*}{0.110} & -0.040 & \multirow{11}{*}{0.032} & -0.025 & -0.048 & 1.281 & -0.061 \\
\hline Q1 & -0.022 & & -0.185 & & -0.043 & & -0.027 & -0.052 & 0.934 & -0.049 \\
\hline Q2 & -0.021 & & -0.182 & & -0.042 & & -0.027 & -0.052 & 0.781 & -0.040 \\
\hline Q3 & -0.018 & & -0.156 & & -0.036 & & -0.024 & -0.044 & 0.642 & -0.029 \\
\hline Q4 & 0.047 & & 0.404 & & 0.094 & & 0.061 & 0.115 & 0.768 & 0.088 \\
\hline Q5 & 0.012 & & 0.105 & & 0.025 & & 0.016 & 0.030 & 0.859 & 0.026 \\
\hline Q6 & 0.009 & & 0.080 & & 0.019 & & 0.012 & 0.022 & 0.990 & 0.022 \\
\hline Q7 & 0.005 & & 0.046 & & 0.011 & & 0.007 & 0.013 & 1.167 & 0.015 \\
\hline Q8 & 0.005 & & 0.039 & & 0.009 & & 0.006 & 0.011 & 1.437 & 0.015 \\
\hline Q9 & 0.002 & & 0.017 & & 0.004 & & 0.002 & 0.005 & 2.006 & 0.009 \\
\hline Q10 & 0.000 & & 0.004 & & 0.001 & & 0.000 & 0.001 & 3.268 & 0.003 \\
\hline \multicolumn{11}{|c|}{ Father reads books regularly_-Boys } \\
\hline Q0 & -0.020 & \multirow{11}{*}{0.094} & -0.171 & \multirow{11}{*}{0.192} & -0.040 & \multirow{11}{*}{-0.036} & 0.026 & -0.007 & 1.965 & -0.014 \\
\hline Q1 & -0.022 & & -0.185 & & -0.043 & & 0.028 & -0.008 & 1.331 & -0.011 \\
\hline Q2 & -0.021 & & -0.182 & & -0.042 & & 0.027 & -0.009 & 1.060 & -0.009 \\
\hline Q3 & -0.018 & & -0.156 & & -0.036 & & 0.022 & -0.009 & 0.783 & -0.007 \\
\hline Q4 & 0.047 & & 0.404 & & 0.094 & & -0.060 & 0.018 & 1.102 & 0.020 \\
\hline Q5 & 0.012 & & 0.105 & & 0.025 & & -0.015 & 0.005 & 1.130 & 0.006 \\
\hline Q6 & 0.009 & & 0.080 & & 0.019 & & -0.011 & 0.004 & 1.279 & 0.005 \\
\hline Q7 & 0.005 & & 0.046 & & 0.011 & & -0.007 & 0.002 & 1.485 & 0.003 \\
\hline Q8 & 0.005 & & 0.039 & & 0.009 & & -0.006 & 0.002 & 1.802 & 0.004 \\
\hline Q9 & 0.002 & & 0.017 & & 0.004 & & -0.002 & 0.001 & 2.474 & 0.002 \\
\hline Q10 & 0.000 & & 0.004 & & 0.001 & & -0.001 & 0.000 & 3.965 & 0.001 \\
\hline
\end{tabular}

small change in the variable $x$, but without changing the effort levels that would be determined by this change. To derive the effect of a variable $x$ on each of the effort levels, we need to know the values of $\frac{\partial e^{C}}{\partial x}, \frac{\partial e^{P}}{\partial x}$, and $\frac{\partial e^{S}}{\partial x}$, that is, we need to solve for the three effort levels the system (10) to (12). Writing it in matrix form, we obtain:

$$
\left[\begin{array}{c}
e_{i}^{C} \\
e_{i}^{P} \\
e_{i}^{S}
\end{array}\right]=\left[\begin{array}{ccc}
1 & -\gamma_{2}^{C} & -\gamma_{3}^{C} \\
-\gamma_{2}^{P} & 1 & -\gamma_{3}^{P} \\
-\gamma_{2}^{S} & -\gamma_{3}^{S} & 1
\end{array}\right]^{-1}\left[\begin{array}{c}
\mathbf{x}_{i}^{C \prime} \boldsymbol{\gamma}_{1}^{C} \\
\mathbf{x}_{i}^{P} \boldsymbol{\gamma}_{1}^{P} \\
\mathbf{x}_{i}^{S} \boldsymbol{\gamma}_{1}^{S}
\end{array}\right]+\left[\begin{array}{c}
v_{i}^{C} \\
v_{i}^{P} \\
\gamma_{i}^{S}
\end{array}\right]
$$

For example, for the child's effort, we have

$$
\frac{\partial e^{C}}{\partial x}=b_{11} \gamma_{1 x}^{C}+b_{12} \gamma_{1 x}^{P}+b_{13} \gamma_{1 x}^{S},
$$

where $b_{11}, b_{12}$, and $b_{13}$ are the elements in the first row of the matrix on the right-hand side of equation (19), and $\gamma_{1 x}^{C}, \gamma_{1 x}^{P}$, and $\gamma_{1 x}^{S}$ are the coefficients of variable $x$ in each of the three equations obtained from table 3 . They are obviously 0 if the variable $x$ is not included in the corresponding equation. There is a similar result for the parents and the school.

This decomposition can be carried out for all control variables. Table 8 reports the marginal effects for ability and 
the "Father reads books regularly" dummy variable. The effects of each variable on child's, parents', and school's efforts are reported in columns 3,5, and 7, respectively.

These two variables differ qualitatively: the total effect (the ninth column) is positive for both. However, whereas ability affects positively both exam results and effort, whether the father reads books regularly has a negative direct effect on qualification (see column 8 in table 8). This negative effect nevertheless is not strong enough to offset the positive effect that "Father reads books regularly" has on the child's and the parents' effort and the school's for girls (see columns 2, 4, and 6).

It is instructive to compare the total effect obtained with this decomposition with the effect obtained from a reduced form, where the probability of qualification $k$, say $\tilde{\pi}_{k}(\cdot)$, is a function of the control variables only: $\tilde{\pi}_{k}(\cdot)=\pi_{k}\left(e^{C}(\cdot)\right.$, $\left.a ; e^{P}(\cdot), s^{P} ; e^{S}(\cdot), s^{S}\right)$. To this end, we have estimated the equivalent of equation (17) without the effort variables:

$$
Q_{i}=\mathbf{x}_{i}^{Q \prime} \boldsymbol{\beta}+u_{i}, \quad i=1, \ldots, n,
$$

where the vector $\mathbf{x}_{i}^{Q}$ contains all the variables, other than efforts, which appear in at least one of equations (9) to (12). Column 11 in table 8 reports the marginal effects calculated from the estimated $\beta$ coefficients in equation (20) denoted as the partial derivatives of the reduced-form probabilities $\tilde{\pi}_{k}(\cdot)$. Column 10 reports the ratio between the coefficients estimated from the reduced form (column 11) and the total effect from the structural system (column 9). We are encouraged in the belief that our procedure to evaluate the effect of effort is sound by the fact that the ratios reported in column 10 are close to 1 , except at most at the extremes of the distribution of the qualification, where it is possible that the lower accuracy of the comparison between the two procedures is due to having fewer observations. This is, of course, a loose argument, as we do not have confidence intervals to indicate whether columns 11 and 9 are indeed the same.

\section{Conclusion}

Intuition suggests that if children, their parents, and their teachers exert more effort, the academic performance of the children improves. Our paper confirms this intuition and qualifies it. At a theoretical level, it illustrates the consequences of the strategic interaction among the participants in the education process. As a simple example shows, if effort levels are strategic substitutes, then an increase in effort by the school may cause a reduction in effort by the students. The model is tested empirically, with interesting results-for example, our finding that the parents' effort is more important than the school's and the children's effort is not necessarily intuitive, though it can be rationalized ex post. The next step is to understand what motivates children, their parents, and their teachers to exert effort. This can allow policymakers to design policies aimed at improving attainment. It may be easier and more effective to stimulate effort in households with low socioeconomic background rather than hope for their economic conditions to change.

The environment where schools operate has clearly changed radically in the past decades in terms of both the incentive system operating within schools and the competitive climate among schools, and understanding which fundamental factors affect the behavior of the agents at the heart of the educational production process is important to be able to evaluate the effects of the changing environment and predict the possible effects of any proposed new policy change.

\section{REFERENCES}

Arnott, Richard, and John Rowse, "Peer Group Effects and Educational Attainment," Journal of Public Economics 32 (1987), 287-305.

Becker, Gary S.,"An Economic Analysis of Fertility," in Demographic and Economic Change in Developed Countries (Princeton, NJ: Princeton University Press, 1960)

Becker, Gary S., and Nigel Tomes, "Child Endowments and the Quantity and Quality of Children," Journal of Political Economy 84 (1976), S143-S162.

Blake, Judith, Family Size and Achievement (Berkeley: University of California Press, 1989).

Bonesrønning, Hans, "The Importance of Student Effort in Education Production: Empirical Evidence from Norway," Department of Economics. Norwegian University of Science and Technology (1998).

"The Determinants of Parental Effort in Education Production: Do Parents Respond to Changes in Class Size?" Economics of Education Review 23 (2004), 1-9.

Bulow, Jeremy I., John D. Geanakoplos, and Paul D. Klemperer, "Multimarket Oligopoly: Strategic Substitutes and Complements," Journal of Political Economv 93 (1985), 488-511.

Cappelli, Peter, and Keith Chauvin, "An Interplant Test of the Efficiency Wage Hypothesis," Ouarterly Journal of Economics 106 (1991), 769-787.

Cardoso, Eliana, and Andre Portela Souza, "The Impact of Cash Transfers on Child Labor and School Attendance in Brazil," University of São Paulo mimeograph (2003).

Carneiro, Pedro, and James Heckman, "Human Capital Policy," in James Heckman, Alan Krueger, and Benjamin Friedman (Eds.), Inequality in America: What Role for Human Capital Policies? (Cambridge, MA: MIT Press, 2005).

Conley, Dalton, Kate Strully, and Neil G. Bennett, "A Pound of Flesh or Just Proxy? Using Twin Differences to Estimate the Effect of Birth Weight on Life Chances," NBER working paper series no. 9901 (2003).

Connolly, Sara, John Micklewright, and Stephen Nickell, "The Occupational Success of Young Men Who Left School at Sixteen," Oxford Economic Papers 44 (1992), 460-479.

Cooley, Jane, "Equilibrium Achievement under Conformity Effects," Department of Economics, Duke University (2004).

Costello, Anna B., and Jason W. Osborne, "Best Practices in Exploratory Factor Analysis: Four Recommendations for Getting the Most from Your Analysis," Practical Assessement Research and Evaluation 10 (2005), 1-9.

CUSSRU, "National Child Development Study Composite File including Selected Perinatal Data and Sweeps One to Five, 1958-1991, 2nd Edition," technical report (Colchester, Essex: City University Social Statistics Research Unit, National Birthday Trust Fund, National Children's Bureau, City University Social Statistics Unit, 2000).

Davidson, Russell, and James G. MacKinnon, Estimation and Inference in Econometrics (New York: Oxford University Press, 1993).

de Bartolome, Charles, "Equilibrium and Inefficiency in a Community Model with Peer Group Effects," Journal of Political Economy 98 (1990), 110-133. 
De Fraja, Gianni, and Pedro Landeras, "Could Do Better: The Effectiveness of Incentives and Competition in Schools," Journal of Public Economics 90 (2006), 189-213.

Dearden, Lorraine, Carl Emmerson, Christine Frayne, and Costas Meghir, "The Impact of Financial Incentives on Education Choice," paper presented at the CEPR meeting, Economics of Education, Paris (2003).

Dearden, Lorraine, Javier Ferri, and Costas Meghir, "The Effect of School Quality on Educational Attainment and Wages," this REVIEW 84 (2002), 1-20.

Epple, Dennis, Richard E. Romano, and H. Sieg, "Peer Effects, Financial Aid, and Selection of Students to Colleges and Universities: An Empirical Analysis," Journal of Applied Econometrics 18 (2003), 501-525.

Ermisch, John, and Marco Francesconi, "Family Matters: Impacts of Family Background on Educational Attainments," Economica 68 (2001), 137-156.

Everitt, Brian S., and Graham Dunn, Applied Multivariate Data Analysis, 2nd ed. (London: Arnold, 2001).

Falk, Armin, and Andrea Ichino, "Clean Evidence on Peer Pressure," European University Institute, Florence (2003).

Fan, Xitao, and Michael Chen, "Parental Involvement and Students' Academic Achievement: A Meta-Analysis," Educational Psvchologv Review 13 (2001), 1-22.

Fryer, Roland G., and Steven D. Levitt, "Understanding the Black-White Test Score Gap in the First Two Years of School," this REvIEw 86 (2004), 447-464.

Fudenberg, Drew, and Jean Tirole, Game Theory (Cambridge, MA: MIT Press, 1991).

Galindo-Rueda, Fernando, and Anna Vignoles, "Class Ridden or Meritocratic? An Economic Analysis of Recent Changes in Britain," Centre for the Economics of Education, London School of Economics 32 (2003).

Galizzi, Monica, and K. Lang, "Relative Wages, Wage Growth, and Quit Behavior," Journal of Labor Economics 16 (1998), 367-391.

Hanushek, Eric A., "The Economics of Schooling: Production and Efficiency in Public Schools," Journal of Economic Literature 23 (1986), 1141-1177.

"The Trade-Off between Child Quantity and Quality," Journal of Political Economy 100 (1992), 84-117.

Harman, Harry H., Modern Factor Analysis, 3rd ed. (Chicago: University of Chicago Press, 1976).

Henderson, Vernon, Peter Mieszkowski, and Yvon Sauvageau, "Peer Group Effects in Educational Production Function," Journal of Public Economics 10 (1978), 97-106.

Hendry, David F., Dynamic Econometrics (New York: Oxford University Press, 1995).

Holmstrom, Bengt R., and Jean Tirole, "The Theory of the Firm" (pp. 61-133), in Richard Schmalensee and Robert D. Willig (Eds.), Handbook of Industrial Organization, vol. 1 (Amsterdam: NorthHolland, 1989).

Hoover-Dempsey, Kathleen V., Angela C. Battiato, Joan M. T. Walker, Richard P. Reed, Jennifer M. DeJong, and Kathleen P. Jones,
"Parental Involvement in Homework," Educational Psvchologist 36 (2001), 195-209.

Ichino, Andrea, and Giovanni Maggi, "Work Environment and Individual Background: Explaining Regional Shirking Differentials in a Large Italian Firm," Ouarterly Journal of Economics 115 (2000), 10571090.

Ichino, Andrea, and Regina Riphahn, "The Effect of Employment Protection on Worker Effort: Absenteeism during and after Probation," Journal of the European Economic Association 3 (2005), 120-143.

JCfLR, "National Child Development Study and 1970 British Cohort Study (BCS70) Follow-Ups, 1999-2000," technical report (Colchester, Essex: Joint Centre for Longitudinal Research, UK Data Archive, 2001).

Kolenikov, Stanislav, and Gustavo Angeles, "The Use of Discrete Data in PCA: Theory, Simulations, and Applications to Socioeconomic Indices," CPC/Measure working paper no. WP-04-85 (2004).

Levacic, Rosalind C., and Anna Vignoles, "Researching the Links between School Resources and Student Outcomes in the UK: A Review of Issues and Evidence," Education Economics 10 (2002), 313-331.

Lewis, H. Gregg, "Union Relative Wage Effects" (pp. 1139-1181), in Orley C. Ashenfelter and Richard Layard (Eds.), Handbook of Labor Economics, vol. 2 (Amsterdam: North-Holland, 1986).

Micklewright, John, "A Note on Household Income Data in NCDS3," NCDS User Support Group, Social Statistics Research Unit, City University, London (1986). "Choice at Sixteen," Economica 56 (1989), 25-39.

Moreland, Richard L., and John M. Levine, "The Composition of Small Groups" (pp. 237-280), in E. J. Lawler, B. Markovsky, C. Ridgeway, and H. Walker (Eds.), Advances in Group Processes, vol. 9 (Greenwich, CT: JAI Press, 1992).

Natriello, Gary, and Edward L. McDill, "Performance Standards, Student Effort on Homework, and Academic Achievement," Sociology of Education 59 (1986), 18-31.

Shapiro, Carl, and Joseph E. Stiglitz, "Equilibrium Unemployment as a Worker Discipline Device," American Economic Review 74 (1984), 433-444.

Steedman, Jane, Examination Results in Selective and Non-Selective Schools: Findings from the National Child Development Study (London: National Children's Bureau, 1983a).

Examination Results in Selective and Non-Selective Schools: Findings from the National Child Development Study, vol. 2-Appendices (London: National Children's Bureau, 1983b).

Stinebrickner, Ralph, and Todd R. Stinebrickner, "The Causal Effect of Studying on Academic Performance," B.E. Journal of Economic Analysis and Policy 8/1 (2008), article 14.

Summers, Anita A., and Barbara L. Wolfe, "Do Schools Make a Difference?" American Economic Review 67 (1977), 639-652.

Trautwein, Ulrich, and Olaf Köller, "The Relationship between Homework and Achievement: Still Much of a Mystery," Educational Psychology Review 15 (2003), 115-145.

Zimmer, Ron W., and Eugenia F. Toma, "Peer Effects in Private and Public Schools Across Countries," Journal of Policy Analvsis and Management 19 (2000), 75-92. 